\title{
SUPRA-PHYSIOLOGICAL LEVELS OF GIBBERELLINS / DELLAS ALTER THE PATTERNING, MORPHOLOGY AND ABUNDANCE OF ROOT HAIRS IN ROOT TIPS OF ARABIDOPSIS THALIANA SEEDLINGS
}

\author{
Iva MCCARTHY-SUÁREZ
}

Hormone Signalling and Plant Plasticity Group. Instituto de Biología Celular y Molecular de Plantas (CSIC-Universidad Politécnica de Valencia). C/ Ingeniero Fausto Elio s/n (46022), Valencia - Spain.

E-mail: ivmcsua@upvnet.upv.es

\begin{abstract}
In spite of the role of gibberellins/DELLAs in leaf hair production, no investigations have assessed their function in the production of root hairs. To this aim, the effects of supra-physiological levels of GAs/DELLAs on the gene expression patterning of the root hair (CPC) and non-hair (GL2, EGL3 and WER) epidermal cell fate markers, and on the distribution, morphology and abundance of root hairs, were studied in root tips of 5-day-old $A$. thaliana seedlings. Results showed that excessive GAs/DELLAs misarranged the $C P C, G L 2, E G L 3$ and $W E R$ gene expression patterning and the location, shape and frequency of root hairs. However, when the gai-1 (GA-insensitive-1) DELLA mutant protein was specifically over-expressed at the root epidermis, no changes in the patterning or abundance of root hairs occurred. Thus, results suggest that, in A. thaliana seedlings, the GAs/DELLAs might regulate the patterning, morphology and abundance of root hairs from the sub-epidermal tissues of the root.
\end{abstract}

Keywords: DELLAs, Gibberellins, root hair morphology, root hair number, root hair patterning.

\section{Introduction}

The epidermal cell organization in roots of $A$. thaliana seedlings, consisting of single rows of hair-bearing cells (Trichoblasts, which lay over the cleft between two cortical cells) alternating with double rows of hairless cells (Atrichoblasts, which lay over just one cortical cell) has been shown to be genetically determined by a complex network of transcription factors and positional signals, such as CAPRICE (CPC), GLABRA2 (GL2), WEREWOLF (WER) and ENHANCER OF GLABRA3 (EGL3), and regulated by auxin, ethylene (ET), abscisic acid (ABA), nitric oxide (NO), brassinosteroids (BRs), cytokinins (CKs) and strigolactones (SLs)) [SILVERMAN \& al. 1998; CAO \& al. 1999; VAN HENGEL \& al. 2004; LOMBARDO \& al. 2006; KAPPUSAMY \& al. 2009; SCHIEFELBEIN \& al. 2009; NIU \& al. 2011; SALAZARHENAO \& al. 2016]. These hormones, in turn, seem to act downstream of the GL2 gene network, permitting root cells to have fate plasticity, i.e., ability to change to the alternative differentiation route at a relatively late state, as it is not cell lineage, but position, and sometimes even a position-independent mechanism, what seems to continuously determine cell fate [GRIERSON \& SCHIEFELBEIN, 2002; SCHIEFELBEIN \& al. 2009; YU \& al. 2017]. Moreover, these hormones mediate the changes in the root hair patterning associated to the plant responses to soil stress without altering the expression of the WER and GL2 epidermal cell fate markers [SCHMIDT \& al. 2000; YANG \& al. 2007; MARTÍN-REJANO \& al. 2011].

Given that the GAs/DELLAs have a role in trichome (leaf hair) production in $A$. thaliana [CHIEN \& SUSSEX, 1996; TRAW \& BERGELSON, 2003] and participate in 
microtubule (MT) cytoskeleton organization [LOCASCIO \& al. 2013], which is essential for the growth of trichomes and root hairs and for establishing the identity and shape of root cells [BAO \& al. 2001], and because there are no reports concerning the hypothetical implication of GAs/DELLAs in the root hair patterning, this study aimed to investigate the effect of excessive levels of these hormones on the distribution and abundance of root hairs in seedlings of $A$. thaliana. In addition, because changes in the levels of auxin, ET, ABA, NO, BRs and SLs have been correlated to alterations in root hair morphology in response to nutritional stresses, such as low availability of P, B or Fe in the soil (longer and branched root hairs) [SCHMIDT \& al. 2000; YANG \& al. 2007; MARTÍN-REJANO \& al. 2011], this work also aimed to determine whether the GAs/DELLAs might have a role in regulating the morphology of root hairs in seedlings of A. thaliana. To this aim, the spatial expression of the GUS or GFP-fused transcripts of the root hair (CPC) and non-hair (GL2, EGL3, WER) epidermal cell fate markers, as well as the arrangement, shape and density of root hairs, were studied in A. thaliana seedlings grown for 5 days under (or harbouring) excessive levels of GAs/DELLAs. Finally, to locate the tissue from which these hormones might hypothetically affect the patterning of root hairs, the root hair distribution was studied in 5-day-old mutant seedlings resulting from expressing the gai-1 DELLA dominant allele in different tissues of the root (UAS (GAL4-UPSTREAM ACTIVATION SEQUENCE) expression directed system lines; Dr. JIM HASSELHOFF'S laboratory). Results of this study suggested that the GAs/DELLAs might be involved in regulating the patterning, morphology and abundance of root hairs in A. thaliana seedlings.

\section{Material and methods}

\section{Plant material and growth conditions}

Arabidopsis thaliana Col (0) seeds were sterilized (70\% Ethanol (v/v) and $0.01 \%$ Triton X-100 (v/v)), sown on half-strength MS medium plates $(0.8 \%(\mathrm{w} / \mathrm{v})$ agar and $1 \%(\mathrm{w} / \mathrm{v})$ sucrose), stratified for 3-4 days $\left(4^{\circ} \mathrm{C}\right.$, darkness), germinated, and grown vertically $\left(22{ }^{\circ} \mathrm{C} ; 5-7\right.$ days) under continuous white light (Percival growth chamber E-30B) (http://www.percivalscientific.com) as described by LEE \& SCHIEFELBEIN (1999).

\section{Hormone and chemical treatments}

Stock solutions of paclobutrazol (PAC, $10 \mathrm{mM}$ in acetone $100 \%(\mathrm{v} / \mathrm{v})), \mathrm{GA}_{4}(1 \mathrm{mM}$ in $100 \%$ ethanol (v/v)) or $\mathrm{GA}_{3}(50 \mathrm{mM}$ in $100 \%$ ethanol (v/v)) were conveniently diluted and added to MS agar medium or water (in the case of liquid incubation experiments) to obtain a final concentration of $0.5 \mu \mathrm{M}$ PAC, $1 \mu \mathrm{M} \mathrm{GA}_{4}$ and $30 \mu \mathrm{M} \mathrm{GA}_{3}$.

\section{Mutant lines}

The spatial patterning of gene expression of the hair (CPC) and non-hair (GL2, EGL3, WER) epidermal cell fate markers in roots of $A$. thaliana seedlings was studied by using their GUS or GFP-fused promoter lines (CPCpro::GUS, GL2pro::GUS, EGL3pro::GUS and WERpro::GFP) as well as those derived from crossing lines harbouring constitutively excessive levels of GAs/DELLAs with the GL2pro::GUS line (GIDIb ox x GL2pro::GUS, gai-1 x GL2pro::GUS, HSp::gai-1 x GL2pro::GUS, pGAI::gai-1:GR x GL2pro::GUS and SCR::gai1:GR x GL2pro::GUS (Ler x GL2pro::GUS background)). The effect of transient increases in the levels of the gai-1 dominant DELLA on the root hair distribution in A. thaliana seedlings was examined by using the heat-shock inducible HSp::gai-1 (which over-expresses the gai-1 DELLA upon heat shock) and dexamethasone (DEXA)-inducible pGAI::gai-1:GR and SCR::gai-1:GR (with glucocorticoid-binding domain) mutant lines. The HSp::gai-1 mutant seedlings were grown at $37^{\circ} \mathrm{C}$ for $4 \mathrm{~h}$ (heat shock) and then at $22^{\circ} \mathrm{C}$ for $2 \mathrm{~h}$ (recovery period), 
whereas the pGAI::gai-1:GR and SCR::gai-1:GR mutant seedlings were incubated in 0.1, 0.2, 0.5, 1.2 or $10 \mu \mathrm{M}$ DEXA for a minimum of $6 \mathrm{~h}$. The root hair distribution was also studied in mutants with excessive levels of GAs/DELLAs (gai-1, GAI-ox (GAI-over-expressing), QD (quadruple DELLA mutant), 5X (quintuple DELLA mutant), GID1b-ox (which over-expresses the GA receptor GID1b (GIBBERELLIN INSENSITIVE DWARF1), in mutants over-expressing gai-1 in different tissues of the root (ML1::gai-1 (epidermis) and UAS expression directed system (GAL4UPSTREAM ACTIVATION SEQUENCE) mutants: UAS:: gai-1 x C24 (control, background); UAS::gai-1 x J0951 (epidermis of the meristematic zone (MZ)); UAS::gai-1 x J2812 (MZ epidermis and cortex); UAS::gai-1 x N9142 (cortex of the elongation zone (EZ)); UAS::gai-1 x M0018 (MZ cortex and endodermis); UAS::gai-1 x J0571 (MZ cortex and endodermis); UAS::gai$1 \times$ Q2393 (all tissues but the endodermis); UAS::gai-1 x Q2500 (MZ endodermis/pericycle); UAS::gai-1 x J0121 (EZ pericycle); UAS::gai-1 x J0631 (all tissues of the EZ); UAS::gai-1 $\mathrm{x}$ $\mathrm{J} 3281$ (vessels)), and in the wer, $c p c$ and $35 S:: C P C$ (cauliflower mosaic virus $35 \mathrm{~S}$ promoter) mutants.

\section{GUS activity assay}

GUS ( $\beta$-glucuronidase) staining of the GL2pro::GUS, CPCpro::GUS and EGL3pro::GUS reporter lines was performed as described by FRIGERIO \& al. (2006), but using $8 \mathrm{mM}$ instead of $2 \mathrm{mM}$ potassium ferro/ferricyanide and incubating the seedlings (15 min to $2 \mathrm{~h}$ ) in the reaction mixture at $4{ }^{\circ} \mathrm{C}$ instead of $37^{\circ} \mathrm{C}$.

\section{Microscopy}

The patterning of the hair/non-hair epidermal cell types in roots of A. thaliana seedlings was studied by staining the roots with $0.67 \mathrm{mg} / \mathrm{ml}$ propidium iodide, by observing the root tips under a Nickon Eclipse E6000 microscope, and by calculating the percentage of hairs/non-hairs at the Trichoblast/Atrichoblast positions (Dr. BENEDICTE DESVOYES' method). The patterning of GL2pro::GUS expression in cross sections of root tips was studied on ultra-thin sections of plastic resin-embedded roots as previously described at Dr. SCHIEFELBEIN Protocols (http://www.mcdb.lsa.umich.edu/labs/schiefel/protocols.html). Seedlings were included in $1 \%$ agarose in $0.1 \mathrm{M}$ sodium phosphate buffer, $\mathrm{pH} 6.8$, and stained for GUS activity. Root-containing blocks were then cut, fixed with $4 \%$ para-formaldehyde in PBS, dehydrated in ethanol series $(15 \%, 30 \%, 50 \%, 75 \%, 95 \%$ and $100 \%, 1 \mathrm{~h}$ each), kept in $100 \%$ ethanol overnight, incubated in Technovit ${ }^{\circledR} 7100$ infiltration solution for 2 days, inserted in gelatine capsules, and embedded for 9 days in Technovit@ 7100 plastic resin (Heraeus Kultzer, Germany). Ultramicrotome (Ultracut E, Reichert Jung, Germany) cross sections of resin-embedded roots were then stained with $0.06 \%(\mathrm{w} / \mathrm{v})$ toluidine blue and observed under a Nikon Eclipse E600 microscope. The WERpro::GFP expression was visualized by using a Leica Confocal Microscope (excitation: $488 \mathrm{~nm}$; detection: 500-530 nm band-path filter for GFP).

\section{Results}

Excessive levels of GAs/DELLAs altered the root hair patterning in seedlings of A. thaliana

To assess whether the GAs/DELLAs might have a role in the root hair patterning of $A$. thaliana seedlings, the spatial gene expression of the root hair (CPC) and non-hair (GL2, EGL3, WER) epidermal cell fate markers was studied in seedlings of the GL2pro::GUS, CPCpro::GUS, EGL3pro::GUS and WERpro::GFP transgenic lines grown for 5 days under supra-physiological levels of GAs/DELLAs (Figure 1A). Results showed that growth under 
excessive levels of GAs/DELLAs altered the normal patterning of gene expression of the root hair/non-hair epidermal cell fate markers (Figure 1A). This was confirmed by analysing the spatial expression of GL2 in the GID1b-ox (which over-expresses the GA receptor GID1b), gai1, HSp::gai-1 (which over-expresses the gai-1 DELLA upon exposure to heat $\left(37^{\circ} \mathrm{C}, 4 \mathrm{~h}\right)$ ), and DEXA-inducible pGAI::gai-1:GR and SCR::gai-1:GR mutants (Figure 1A). Moreover, the alteration of the GL2pro::GUS expression pattern under excessive levels of GAs/DELLAs was corroborated in ultra-thin sections of resin-embedded roots (Figure 1B).

An analysis of the distribution of the root hair and non-hair cells relative to their position over the cortex cells showed that excessive levels of GAs/DELLAs impaired the correct positioning of the root hair/non-hair cells (Tables 1 and 2), giving rise to ectopic root hairs (at the Atrichoblast position) and ectopic root non-hairs (at the Trichoblast position) (Figures $2 \mathrm{~A}$ and $2 \mathrm{~B})$. Interestingly, treatment with $\mathrm{GA}_{4}(1 \mu \mathrm{M})$ reduced the percentage of ectopic root hair cells in the hairy mutant $35 S:: C P C$, whereas treatment with PAC $(0.5 \mu \mathrm{M})$ slightly decreased the percentage of ectopic root non-hair cells in the bald mutant $c p c$ (Table 2). In accordance with these changes, growing A. thaliana seedlings under supra-physiological levels of GAs/DELLAs for 5 days altered the arrangement of root hairs in root tips, giving rise to ectopic root hairs (in a non-hair row), ectopic root non-hairs (in a hair row) and adjacent root hair rows (Figures 3A and 3B). This was confirmed in the gai-1, QD, 5X, GID1b-ox, pGAI::gai-1:GR and SCR::gai-1:GR mutants (Figures $3 \mathrm{~A}$ and $3 \mathrm{~B}$ ).

To ascertain from which particular tissue of the root the GAs/DELLAs might be affecting the root hair patterning, the positioning of the root hair/non-hair cells over the root cortex cells and the distribution of root hairs were studied in A. thaliana transgenic seedlings expressing the gai-1 DELLA allele in different tissues of the root (Figures 2B, 3A and 3B; Table 2 ). Results showed that the root hair distribution changed when gai-1 was over-expressed at the cortex, endodermis or pericycle of the meristematic (MZ) or elongation (EZ) zones of the root (J2812 > gai-1, M0018 > gai-1, Q2500 > gai-1, J0121 > gai-1, Q2393 > gai-1 and J0631 > gai-1 lines), but not when gai-1 was over-expressed at the root epidermis (J0951 > gai-1 and $M L 1:: g a i-1$ lines) (Figure 3A). In fact, the gene expression pattern of GL2 did not change when gai-1 was over-expressed at the epidermis (ML1::gai-1 line) (Figure 1). Moreover, ectopic hairs, ectopic non-hairs and adjacent hair rows appeared when gai-1 was over-expressed at the cortex (J2812 >> gai-1 and N9142 >> gai-1 lines), endodermis (M0018 >> gai-1 and J0571 >> gai-1 lines) or pericycle (Q2500 > gai-1 and J0121 > gai-1 lines) of the root, or in all root tissues but the endodermis (Q2393 》 gai-1 line) (Figures 2B, 3A and 3B). However, when gai1 was over-expressed in the root vessels (J3281 > gai-1 line), the growth of the root and the production of root hairs stopped (Figure 3A).

\section{Excessive levels of GAs/DELLAs altered the morphology, length and abundance of root hairs in root tips of $A$. thaliana seedlings}

Excessive levels of GAs/DELLAs also modified the morphology of Trichoblasts and root hairs in root tips of $A$. thaliana seedlings, frequently giving rise to two-haired cells, twotipped hairs and branched hairs (Figure 4). In addition, excessive levels of GAs/DELLAs altered the length and density of root hairs. Whereas high levels of DELLAs increased the length and number of hairs near the root tip, high levels of GAs had the opposite effect (Figures 5A and $5 \mathrm{~B}$; Table 3). Moreover, root hair abundance in root tips of $A$. thaliana seedlings increased when gai-1 was over-expressed at the cortex (J2812 > gai-1), endodermis (M0018 > gai-1) or pericycle $(\mathrm{Q} 2500 \gg$ gai-1 and J0121 > gai-1) of the root, but not when gai-1 was overexpressed at the epidermis of the root MZ (J0951 > gai-1) or the cortex of the root EZ (N9142 
> gai-1) (Table 3). Also, treatment of the bald mutant $c p c$ with PAC slightly increased the root hair frequency (and length) near the root tip, whereas treatment of the hairy mutants wer and $35 S: \because C P C$ with $\mathrm{GA}_{4}$ reduced it (Figure 5B; Table 3).

High levels of GAs/DELLAs also altered the abundance of root hairs in the radial dimension of the root tips (Tables 4 and 5). The number of root hairs per root cross section, calculated as the summary of root hairs at the Trichoblast and Atrichoblast positions (or the summary of root hairs and ectopic root hairs per root cross section) increased under excessive DELLAs (PAC, gai-1) but decreased in the $5 X$ mutant (Table 5). On the other hand, the number of root non-hairs per root cross section, calculated as the summary of root non-hairs at the Atrichoblast and Trichoblast positions (or the summary of root non-hairs and ectopic root nonhairs per root cross section), decreased under excessive DELLAs, but experienced an enhancement in the $5 X$ mutant (Table 5). Thus, the estimated abundance of root hairs in the radial dimension of the root tips seemed to increase under excessive DELLAs, but to decrease under excessive GAs.

Table 1. Distribution of the root hair and non-hair cells at the Trichoblast/Atrichoblast positions in root tips of 5-day-old A. thaliana seedlings grown under (or harbouring) excessive levels of GAs/DELLAs. Numbers in parenthesis refer to the number of cells analyzed. At least 15-20 roots were used per treatment.

\begin{tabular}{|c|c|c|c|c|}
\hline & \multicolumn{2}{|c|}{ Trichoblast position } & \multicolumn{2}{|c|}{ Atrichoblast position } \\
\hline & Hair Cell (\%) & $\begin{array}{c}\text { Non-Hair cell } \\
(\%)\end{array}$ & Hair Cell (\%) & Non-Hair cell \\
\hline Col (0) (MS) & $97.5 \pm 0.7(73)$ & $\begin{array}{c}2.5 \pm 0.7 \\
(2)\end{array}$ & $\begin{array}{l}0 \pm 0 \\
(0)\end{array}$ & $\begin{array}{c}100 \pm 0 \\
(75)\end{array}$ \\
\hline PAC $(0.5 \mu \mathrm{M})$ & $77.4 \pm 5.7(109)$ & $22.6 \pm 5.7(32)$ & $36.7 \pm 8.2(80)$ & $63.3 \pm 8.2(138)$ \\
\hline $\mathbf{G A}_{4}(1 \mu M)$ & $\begin{array}{c}81 \pm 2.7 \\
(83)\end{array}$ & $\begin{array}{c}19 \pm 2.7 \\
(20)\end{array}$ & $\begin{array}{l}12.5 \pm 3.5 \\
(5)\end{array}$ & $87.5 \pm 3.5(35)$ \\
\hline $\begin{array}{l}\text { PAC (0.5 } \mu \mathrm{M})+\mathrm{GA}_{4} \\
(1 \mu \mathrm{M})\end{array}$ & $\begin{array}{c}94 \pm 4.2 \\
(71) \\
\end{array}$ & $\begin{array}{c}6 \pm 4.2 \\
(5) \\
\end{array}$ & $\begin{array}{c}5 \pm 2.8 \\
(4) \\
\end{array}$ & $\begin{array}{c}95 \pm 2.8 \\
(71) \\
\end{array}$ \\
\hline Ler & $95.8 \pm 2.2(167)$ & $\begin{array}{l}4.2 \pm 2.2 \\
(7)\end{array}$ & $\begin{array}{l}4.5 \pm 3.5 \\
(6)\end{array}$ & $95.5 \pm 3.5(120)$ \\
\hline gai-1 & $82.7 \pm 4.5(75)$ & $17.3 \pm 4.5(16)$ & $\begin{array}{l}40.4 \pm 5 \\
(55)\end{array}$ & $\begin{array}{l}59.6 \pm 5 \\
(81)\end{array}$ \\
\hline$Q D$ & $78.8 \pm 4.5(126)$ & $21.2 \pm 4.5(34)$ & $\begin{array}{l}24 \pm 4.9 \\
(38)\end{array}$ & $\begin{array}{l}76 \pm 4.9 \\
(122)\end{array}$ \\
\hline pGAI::gai-1:GR (MS) & $93.5 \pm 2.1(41)$ & $\begin{array}{l}6.5 \pm 2.1 \\
\text { (3) }\end{array}$ & $\begin{array}{c}25 \pm 7.1 \\
(10)\end{array}$ & $\begin{array}{c}75 \pm 7.1 \\
(30)\end{array}$ \\
\hline $\begin{array}{l}\text { pGAI:::gai-1:GR } \\
\text { (10 } \mu \mathrm{M} \text { DEXA) }\end{array}$ & $\begin{array}{c}78 \pm 2.8 \\
(38) \\
\end{array}$ & $\begin{array}{c}22 \pm 2.8 \\
(11) \\
\end{array}$ & $50.5 \pm 6.4(22)$ & $49.5 \pm 6.4(22)$ \\
\hline SCR::gai-1:GR (MS) & $83.8 \pm 3.3(36)$ & $\begin{array}{c}16.2 \pm 3.3 \\
(7)\end{array}$ & $\begin{array}{c}35 \pm 6.2 \\
(13)\end{array}$ & $\begin{array}{l}65 \pm 6.2 \\
(25)\end{array}$ \\
\hline $\begin{array}{l}\text { SCR::gai-1:GR } \\
(0.1 \mu \mathrm{M} \text { DEXA) }\end{array}$ & $\begin{array}{c}67 \pm 12.7 \\
(30)\end{array}$ & $\begin{array}{c}33 \pm 12.7 \\
(15)\end{array}$ & $\begin{array}{l}15 \pm 7.1 \\
(6)\end{array}$ & $\begin{array}{l}85 \pm 7.1 \\
(34)\end{array}$ \\
\hline
\end{tabular}




\section{SUPRA-PHYSIOLOGICAL LEVELS OF GIBBERELLINS / DELLAS ALTER THE PATTERNING ...}

Table 2. Percentage of ectopic root hair/non-hair cells at the Trichoblast/Atrichoblast positions in root tips of 5-day-old $A$. thaliana seedlings grown under (or harbouring) excessive levels of GAs/DELLAs. *Seedlings analyzed at $48 \mathrm{~h}$ after a heat-shock experiment $\left(37^{\circ} \mathrm{C}, 4 \mathrm{~h}\right)$. GL2pro::GUS $\left(22^{\circ} \mathrm{C}\right)$ : control seedlings grown at $22^{\circ} \mathrm{C}$ for $4 \mathrm{~h}$. GL2pro::GUS $\left(37^{\circ} \mathrm{C}\right)$ : control seedlings grown at $37{ }^{\circ} \mathrm{C}$ for $4 \mathrm{~h}$ (ectopic root hair cells might have appeared due to heat stress). HSp::gai-1 x GL2pro::GUS (37 $\left.{ }^{\circ} \mathrm{C}\right)$ : inducible gai-1 mutant seedlings grown at $37^{\circ} \mathrm{C}$ for $4 \mathrm{~h}$. The number of ectopic root hair and non-hair cells from a single experiment is shown in parenthesis.

\begin{tabular}{|c|c|c|c|c|}
\hline & \multicolumn{2}{|c|}{ Trichoblast position } & \multicolumn{2}{|c|}{ Atrichoblast position } \\
\hline & $\begin{array}{l}\mathbf{N}^{\circ} \text { epidermal } \\
\text { cells examined }\end{array}$ & $\begin{array}{c}\% \text { Ectopic } \\
\text { root non-hair } \\
\text { cells } \\
\end{array}$ & $\begin{array}{l}\mathrm{N}^{\circ} \text { epidermal } \\
\text { cells examined }\end{array}$ & $\begin{array}{c}\text { \% Ectopic } \\
\text { root hair } \\
\text { cells }\end{array}$ \\
\hline Ler & 41 & $2(1)$ & 30 & $7(2)$ \\
\hline $5 X$ & 20 & $35(7)$ & 20 & $0(0)$ \\
\hline GAI-ox & 15 & $7(1)$ & 15 & $53(8)$ \\
\hline GL2pro::GUS $\left(22^{\circ} C\right)^{*}$ & 30 & $0(0)$ & 29 & $0(0)$ \\
\hline GL2pro::GUS $\left(37^{\circ} \mathrm{C}\right) *$ & 30 & $7(2)$ & 30 & $30(9)$ \\
\hline $\begin{array}{l}\text { Hsp::gai-1 } x \\
\text { GL2pro::GUS }\left(37^{\circ} \mathrm{C}\right)^{*}\end{array}$ & 29 & $28(8)$ & 27 & $44(12)$ \\
\hline wer & 28 & $32(9)$ & 36 & $50(18)$ \\
\hline $\operatorname{wer}(1 \mu \mathrm{M} \mathrm{GA} 4)$ & 30 & $20(6)$ & 29 & $72(21)$ \\
\hline cpc & 28 & $64(18)$ & 28 & $21(6)$ \\
\hline$c p c(0.5 \mu \mathrm{M}$ PAC $)$ & 28 & $54(15)$ & 28 & $4(1)$ \\
\hline $35 S:: C P C$ & 30 & $23(7)$ & 30 & $60(18)$ \\
\hline $35 S:: C P C(1 \mu \mathrm{M} \mathrm{GA} 4)$ & 30 & $13(4)$ & 29 & $17(5)$ \\
\hline SCR::gai-1:GR (MS) & 21 & $19(4)$ & 20 & $30(6)$ \\
\hline $\begin{array}{l}\text { SCR::gai-1:GR } \\
(0.2 \mu \mathrm{M} \text { DEXA) }\end{array}$ & 19 & $21(4)$ & 19 & $26(5)$ \\
\hline $\begin{array}{l}\text { SCR::gai-1:GR } \\
(0.5 \mu \mathrm{M} \text { DEXA) } \\
\end{array}$ & 20 & $30(6)$ & 18 & $22(4)$ \\
\hline $\begin{array}{l}\text { SCR::gai-1:GR } \\
(1.2 \mu \mathrm{M} \text { DEXA) }\end{array}$ & 10 & $20(2)$ & 10 & $40(4)$ \\
\hline $\begin{array}{l}\text { UAS::gai } 1 \times C 24 \\
\text { (control) }\end{array}$ & 50 & $0(0)$ & 44 & $0(0)$ \\
\hline ML1::gai-1 & 41 & $2(1)$ & 30 & $3(1)$ \\
\hline UAS::gai-1 x J0951 & 60 & $0(0)$ & 60 & $0(0)$ \\
\hline UAS::gai-1 x J2812 & 30 & $10(3)$ & 30 & $50(15)$ \\
\hline UAS::gai-1 x Q2393 & 9 & $22(2)$ & 16 & $63(10)$ \\
\hline
\end{tabular}




\section{Iva MCCARTHY-SUÁREZ}

Table 3. Length and abundance of root hairs in root tips of 5-day-old $A$. thaliana seedlings grown under (or harbouring) excessive levels of GAs/DELLAs. Analyses of hair length and abundance were performed on micrographs of root tips of $A$. thaliana seedlings (4X). (*) Seedlings analyzed at $24 \mathrm{~h}$ and $48 \mathrm{~h}$ after a heat-shock experiment $\left(37^{\circ} \mathrm{C}, 4 \mathrm{~h}\right)$. Analyses of hair abundance performed at $31.5 \mathrm{X}$ (lens; Control, PAC and GA4), 3.2X (lens; Ler, gai-1 and QD) or 4X (microscope; other mutants and UAS::gai-1 lines).

\begin{tabular}{|c|c|c|c|c|}
\hline & $\begin{array}{c}\text { Hairs } \\
\text { analyzed }\end{array}$ & $\begin{array}{l}\text { Hair Length } \\
(\mu \mathrm{m})\end{array}$ & $\begin{array}{c}\text { Roots } \\
\text { examined }\end{array}$ & $\begin{array}{l}\mathbf{N}^{\circ} \text { Root Hairs } \\
\text { per field }\end{array}$ \\
\hline Col (0) (MS) & 69 & $209 \pm 121(100 \%)$ & 17 & $38 \pm 8(100 \%)$ \\
\hline Col (0) $(0.5 \mu \mathrm{M}$ PAC) & 94 & $270 \pm 128(129 \%)$ & 19 & $54 \pm 12(142 \%)$ \\
\hline $\operatorname{Col}(0)\left(1 \mu M \mathbf{G A}_{4}\right)$ & 37 & $178 \pm 93(85 \%)$ & 18 & $31 \pm 8(82 \%)$ \\
\hline Ler & 45 & $201 \pm 99(100 \%)$ & 5 & $43 \pm 7(100 \%)$ \\
\hline gai-1 & 120 & $397 \pm 186(198 \%)$ & 3 & $56 \pm 1(130 \%)$ \\
\hline$Q D$ & 25 & $139 \pm 85(69 \%)$ & 3 & $24 \pm 5(56 \%)$ \\
\hline GID1b-ox & 14 & $80 \pm 25(40 \%)$ & 6 & $28 \pm 8(88 \%)$ \\
\hline GID1b-ox $(30 \mu \mathrm{M} \mathrm{GA})$ & 10 & $64 \pm 35(32 \%)$ & 3 & $18 \pm 6(57 \%)$ \\
\hline Hsp::gai-1 $\left(22^{\circ} \mathrm{C}\right)$ at $24 \mathrm{~h}(*)$ & 6 & $55 \pm 14(100 \%)$ & 1 & $18 \pm 0(100 \%)$ \\
\hline Hsp::gai-1 $\left(37^{\circ} \mathrm{C}\right)$ at $24 \mathrm{~h}\left({ }^{*}\right)$ & 11 & $405 \pm 208(201 \%)$ & 2 & $32 \pm 4(178 \%)$ \\
\hline Hsp::gai-1 $\left(37^{\circ} \mathrm{C}\right)$ at $48 \mathrm{~h}\left({ }^{*}\right)$ & 23 & $411 \pm 165(204 \%)$ & 3 & $83 \pm 31(459 \%)$ \\
\hline pGAI::gai-1:GR (MS, 30h) & 40 & $270 \pm 118(100 \%)$ & 4 & $56 \pm 7(100 \%)$ \\
\hline $\begin{array}{l}\text { pGAI::gai-1:GR } \\
(0.5 \mu \mathrm{M} \text { DEXA, 30h) }\end{array}$ & 57 & $314 \pm 177(116 \%)$ & 8 & $79 \pm 17(142 \%)$ \\
\hline SCR::gai-1:GR (MS, 3d) & 30 & $245 \pm 87(100 \%)$ & 3 & $49 \pm 20(100 \%)$ \\
\hline $\begin{array}{l}\text { SCR::gai }-1: G R \\
(0.5 \mu \mathrm{M} \text { DEXA, 3d) }\end{array}$ & 35 & $507 \pm 173(207 \%)$ & 5 & $76 \pm 31(154 \%)$ \\
\hline wer (MS) & 24 & $192 \pm 88(100 \%)$ & 3 & $91 \pm 12(100 \%)$ \\
\hline wer $(0.5 \mu \mathrm{M}$ PAC $)$ & 8 & $243 \pm 134(127 \%)$ & 3 & $125 \pm 29(137 \%)$ \\
\hline wer $(1 \mu \mathrm{M} \mathrm{GA})$ & 6 & $133 \pm 23(70 \%)$ & 3 & $70 \pm 5(77 \%)$ \\
\hline cpc (MS) & 7 & $104 \pm 29(100 \%)$ & 3 & $17 \pm 1(100 \%)$ \\
\hline$c p c(0.5 \mu \mathrm{M}$ PAC $)$ & 9 & $213 \pm 92(204 \%)$ & 3 & $18 \pm 2(106 \%)$ \\
\hline$c p c(1 \mu \mathrm{M} \mathrm{GA})$ & 8 & $88 \pm 51(85 \%)$ & 7 & $11 \pm 3(65 \%)$ \\
\hline UAS::gai-1 x C24 (control) & 20 & $161 \pm 105(100 \%)$ & 2 & $48 \pm 23(100 \%)$ \\
\hline UAS::gai-1 x J0951 & 34 & $240 \pm 118(149 \%)$ & 3 & $49 \pm 13(101 \%)$ \\
\hline UAS::gai-1 x J2812 & 59 & $243 \pm 118(151 \%)$ & 9 & $77 \pm 26(161 \%)$ \\
\hline UAS::gai-1 x J0571 & 25 & $586 \pm 273(364 \%)$ & 2 & $60 \pm 11(125 \%)$ \\
\hline UAS::gai-1 x M0018 & 90 & $685 \pm 195(425 \%)$ & 10 & $92 \pm 26(192 \%)$ \\
\hline UAS::gai-1 x Q2500 & 37 & $680 \pm 189(422 \%)$ & 2 & $96 \pm 12(200 \%)$ \\
\hline UAS::gai-1 x Q2393 & 48 & $272 \pm 146(169 \%)$ & 4 & $67 \pm 26(140 \%)$ \\
\hline UAS:gai-1 $x$ N9142 & 21 & $195 \pm 97(121 \%)$ & 2 & $30 \pm 1(63 \%)$ \\
\hline UAS::gai-1 x J0121 & 47 & $233 \pm 120(145 \%)$ & 5 & $67 \pm 13(140 \%)$ \\
\hline UAS::gai-1 x J0631 & 8 & $386 \pm 129(240 \%)$ & 2 & $96 \pm 15(200 \%)$ \\
\hline
\end{tabular}




\section{SUPRA-PHYSIOLOGICAL LEVELS OF GIBBERELLINS / DELLAS ALTER THE PATTERNING ...}

Table 4. Percentage and estimated number of epidermal cells at the Trichoblast/Atrichoblast positions per root cross section in 5-day-old A. thaliana seedlings grown under (or harbouring) excessive levels of GAs/DELLAs. Analyses performed on micrographs of cross sections of resin-embedded roots (40X).

\begin{tabular}{lcccccc}
\hline & $\begin{array}{c}\mathbf{N}^{\mathbf{0}} \text { root } \\
\text { cross } \\
\text { sections } \\
\text { examined }\end{array}$ & $\begin{array}{c}\text { Epidermal } \\
\text { Cells at } \\
\text { Trichoblast } \\
\text { position }\end{array}$ & $\begin{array}{c}\text { \% Epidermal } \\
\text { Cells at } \\
\text { Atrichoblast } \\
\text { position }\end{array}$ & $\begin{array}{c}\text { Average } \\
\text { number of } \\
\text { epidermal } \\
\text { cells per } \\
\text { root cross } \\
\text { section }\end{array}$ & $\begin{array}{c}\text { Predicted No } \\
\text { of epidermal } \\
\text { cells at the } \\
\text { Trichoblast } \\
\text { position per } \\
\text { root radial } \\
\text { section }\end{array}$ & $\begin{array}{c}\text { Predicted } \mathbf{N}^{\mathbf{0}} \\
\text { cells at the } \\
\text { Atrichoblast } \\
\text { position per } \\
\text { root radial } \\
\text { section }\end{array}$ \\
\hline Control & 19 & $35.5 \pm 0.8$ & $64.5 \pm 0.8$ & $23 \pm 1$ & $8(100 \%)$ & $15(100 \%)$ \\
\hline $\begin{array}{l}\text { PAC }(\mathbf{0 . 5} \\
\boldsymbol{\mu M})\end{array}$ & 25 & $29.8 \pm 2$ & $70.2 \pm 2$ & $27 \pm 2$ & $8(100 \%)$ & $19(127 \%)$ \\
\hline $\begin{array}{l}\text { GA4 } \\
(\mathbf{1} \boldsymbol{\mu M})\end{array}$ & 20 & $36 \pm 3$ & $64 \pm 3$ & $23 \pm 2$ & $8(100 \%)$ & $15(100 \%)$ \\
\hline Ler & 20 & $39.1 \pm 3.8$ & $60.9 \pm 3.8$ & $21 \pm 2$ & $8(100 \%)$ & $13(100 \%)$ \\
\hline gai-1 & 19 & $34.9 \pm 1$ & $65.1 \pm 0.9$ & $23 \pm 1$ & $8(100 \%)$ & $15(115 \%)$ \\
\hline QD & 31 & $40.8 \pm 6.2$ & $59.2 \pm 6.2$ & $23 \pm 1$ & $9(113 \%)$ & $14(108 \%)$ \\
\hline $\mathbf{5 X}$ & 22 & $41.5 \pm 2.4$ & $58.5 \pm 2.4$ & $20 \pm 3$ & $8(100 \%)$ & $12(92 \%)$ \\
\hline
\end{tabular}

Table 5. Estimated number of root hairs and root non-hairs per root cross section in root tips of 5-day-old A. thaliana seedlings grown under (or harbouring) excessive levels of GAs/DELLAs. Calculations were made by considering the data of Table 1 (distribution of hair and non-hair cells at the Trichoblast/Atrichoblast positions), Table 2 (percentage of ectopic root hair/non-hair cells at the Atrichoblast/Trichoblast positions) and Table 4 (average number of epidermal cells per root cross section, estimated number of epidermal cells at the Trichoblast position per root cross section, and estimated number of epidermal cells at the Atrichoblast position per root cross section). Estimated number of root hairs per root cross section $=$ [hairs at the Trichoblast position + hairs at the Atrichoblast position] . Estimated number of root non-hairs per root cross section $=$ [non-hairs at the Atrichoblast position + nonhairs at the Trichoblast position].

\begin{tabular}{lcccccc}
\hline & $\begin{array}{c}\text { Trichoblast position } \\
\text { Hairs } \\
\text { per root } \\
\text { cross } \\
\text { section }\end{array}$ & $\begin{array}{c}\text { Non-hairs } \\
\text { per root } \\
\text { cross } \\
\text { section }\end{array}$ & $\begin{array}{c}\text { Atrichoblast position } \\
\text { Hairs per } \\
\text { root cross } \\
\text { section }\end{array}$ & $\begin{array}{c}\text { Non-hairs } \\
\text { per root } \\
\text { cross } \\
\text { section }\end{array}$ & $\begin{array}{c}\text { Estimated } \\
\mathbf{N}^{\mathbf{0}} \text { of } \\
\text { Root Hairs } \\
\text { per root } \\
\text { cross section }\end{array}$ & $\begin{array}{c}\text { Estimated No of } \\
\text { Non-root hairs } \\
\text { per root cross } \\
\text { section }\end{array}$ \\
\hline Control & 8 & 0 & 0 & 15 & $8(100 \%)$ & $15(100 \%)$ \\
\hline PAC $(\mathbf{0 . 5} \boldsymbol{\mu M})$ & 6 & 2 & 7 & 12 & $13(163 \%)$ & $14(93 \%)$ \\
\hline GA4 $(\mathbf{1} \boldsymbol{\mu M})$ & 6 & 2 & 2 & 13 & $8(100 \%)$ & $15(100 \%)$ \\
\hline Ler & 8 & 0 & 1 & 12 & $9(100 \%)$ & $12(100 \%)$ \\
\hline gai-1 & 7 & 1 & 6 & 9 & $13(144 \%)$ & $10(83 \%)$ \\
\hline QD & 7 & 2 & 3 & 11 & $10(111 \%)$ & $13(108 \%)$ \\
\hline $\mathbf{5 X}$ & 5 & 3 & 0 & 12 & $5(56 \%)$ & $15(125 \%)$ \\
\hline
\end{tabular}




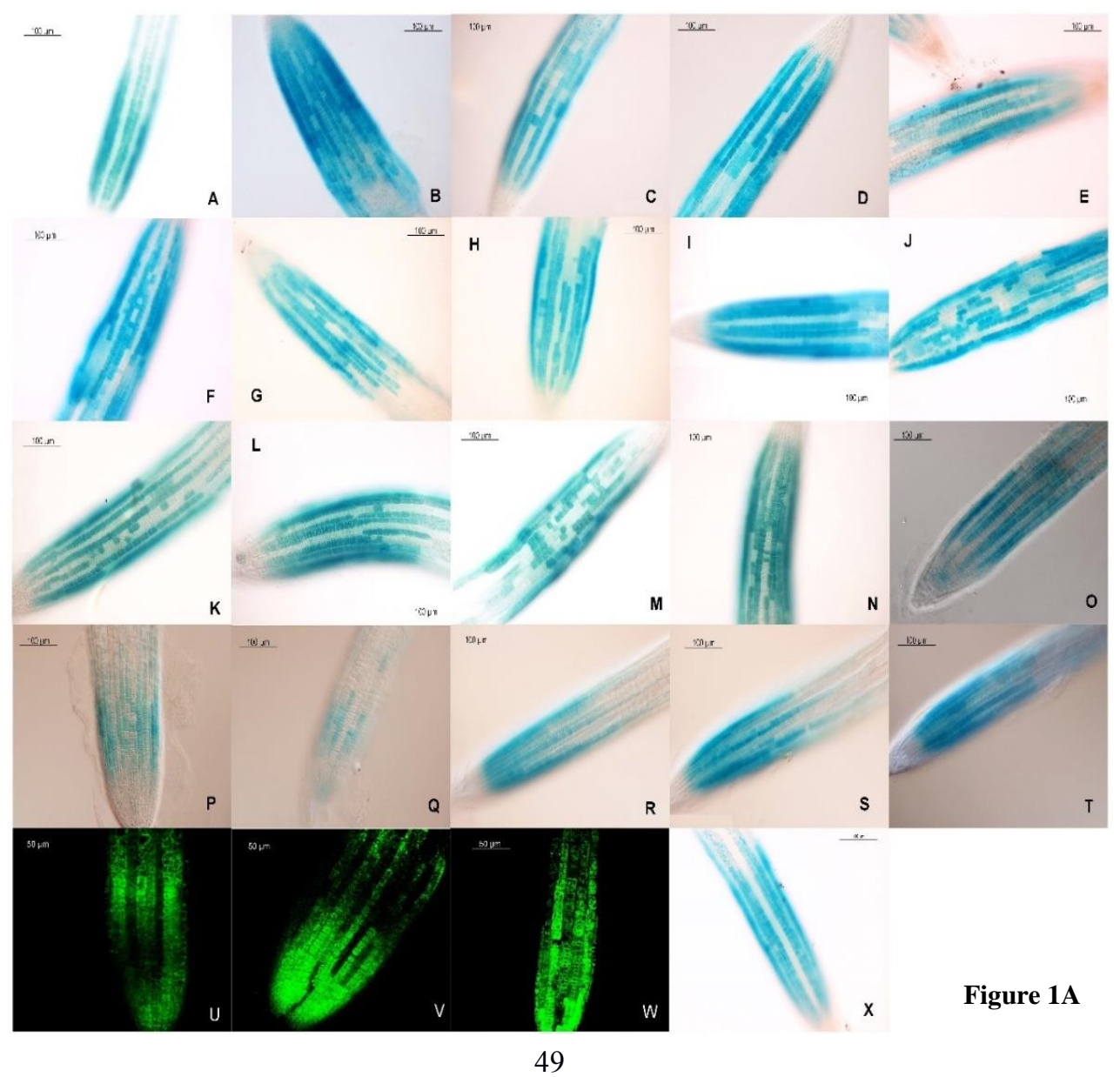


SUPRA-PHYSIOLOGICAL LEVELS OF GIBBERELLINS / DELLAS ALTER THE PATTERNING ...

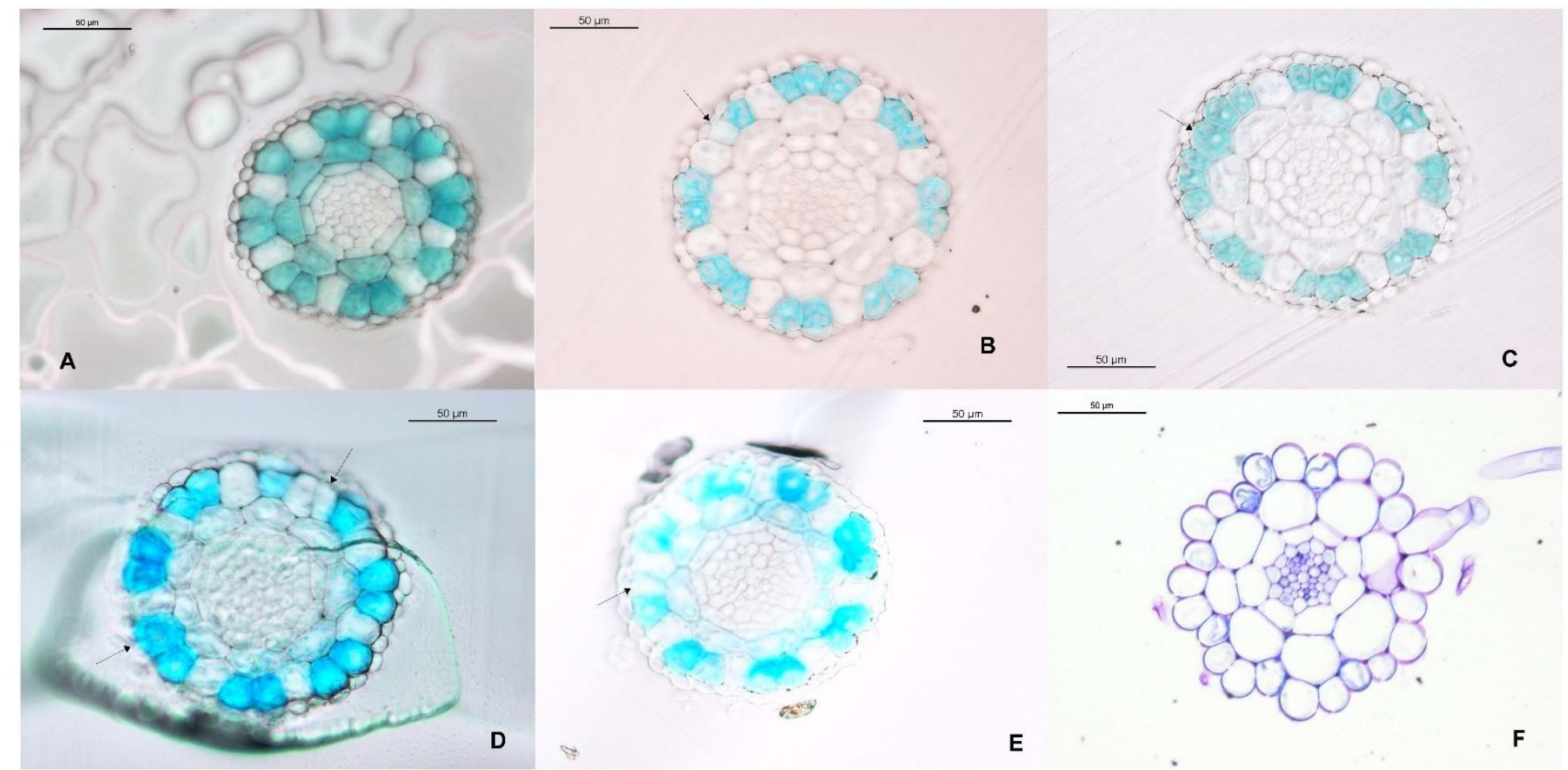

Figure 1B 
Iva MCCARTHY-SUÁREZ

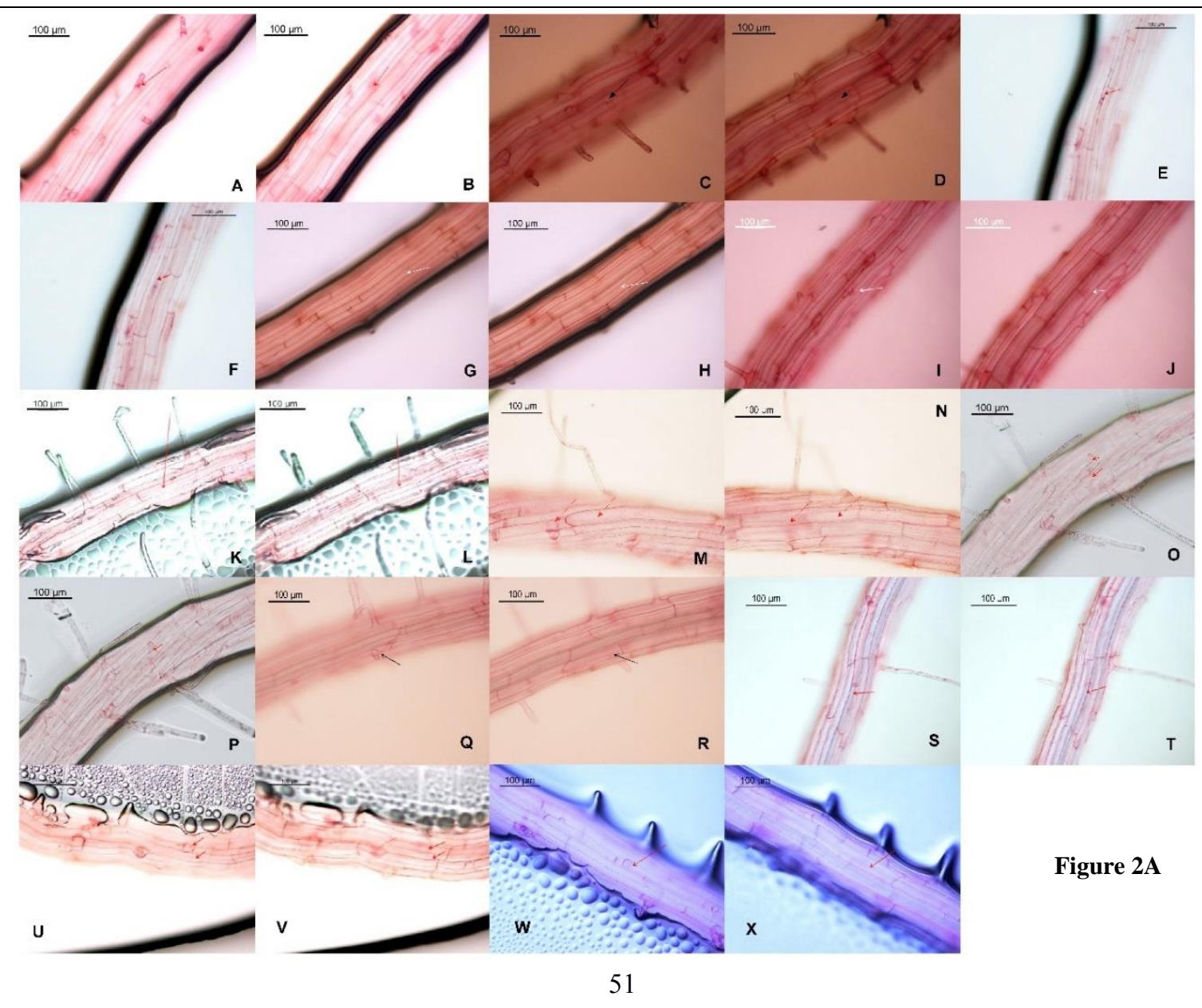


SUPRA-PHYSIOLOGICAL LEVELS OF GIBBERELLINS / DELLAS ALTER THE PATTERNING ...

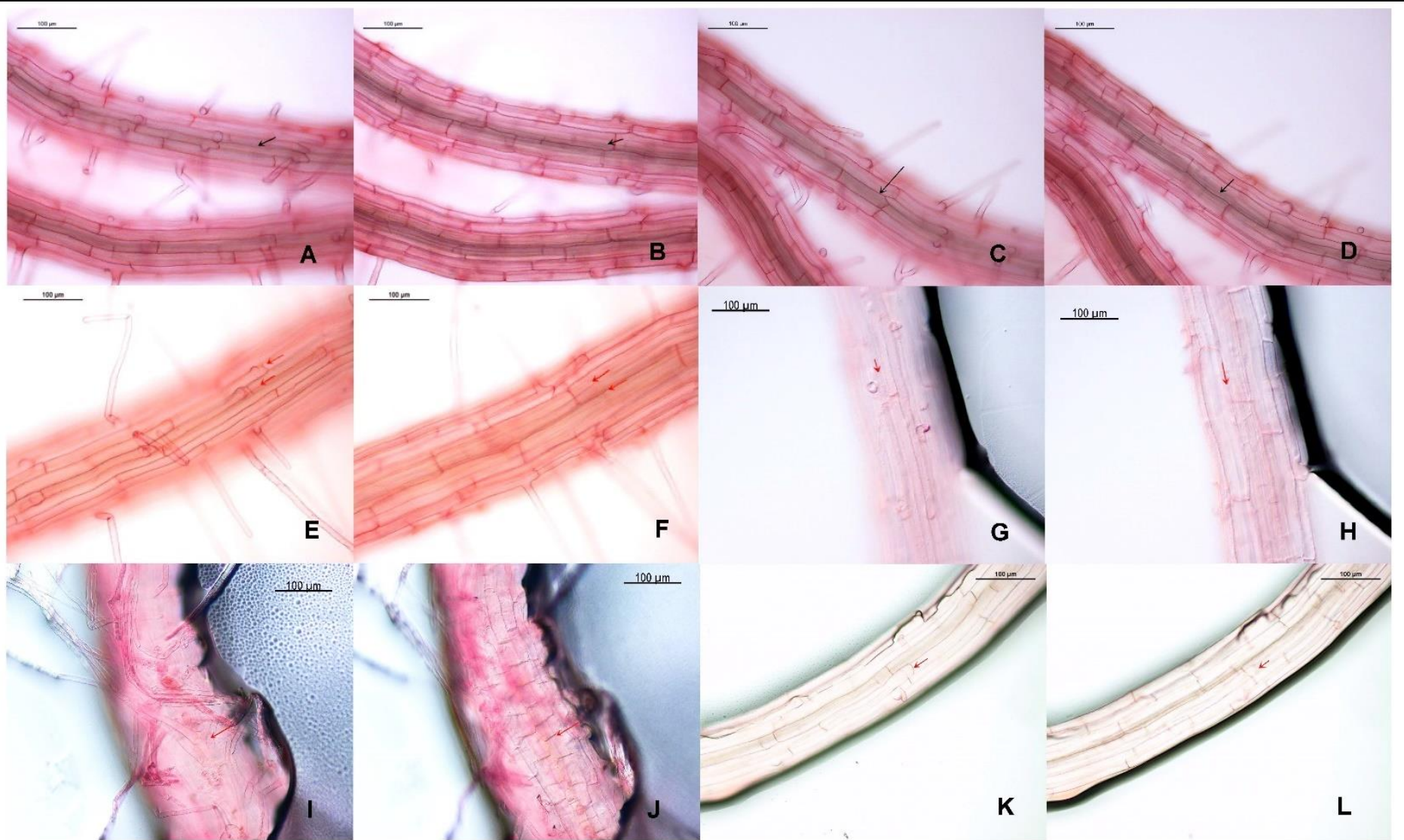

Figure 2B 


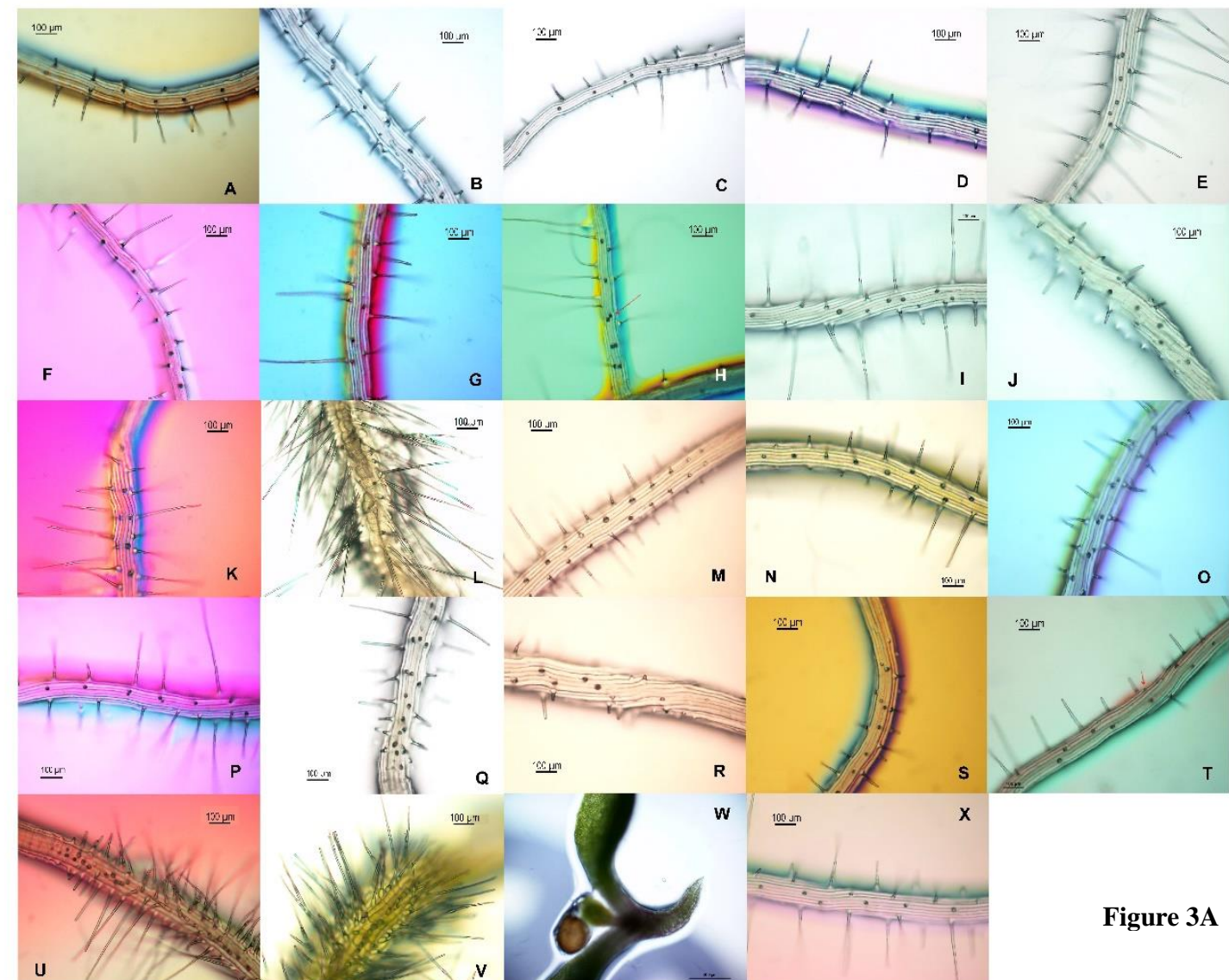


SUPRA-PHYSIOLOGICAL LEVELS OF GIBBERELLINS / DELLAS ALTER THE PATTERNING ...

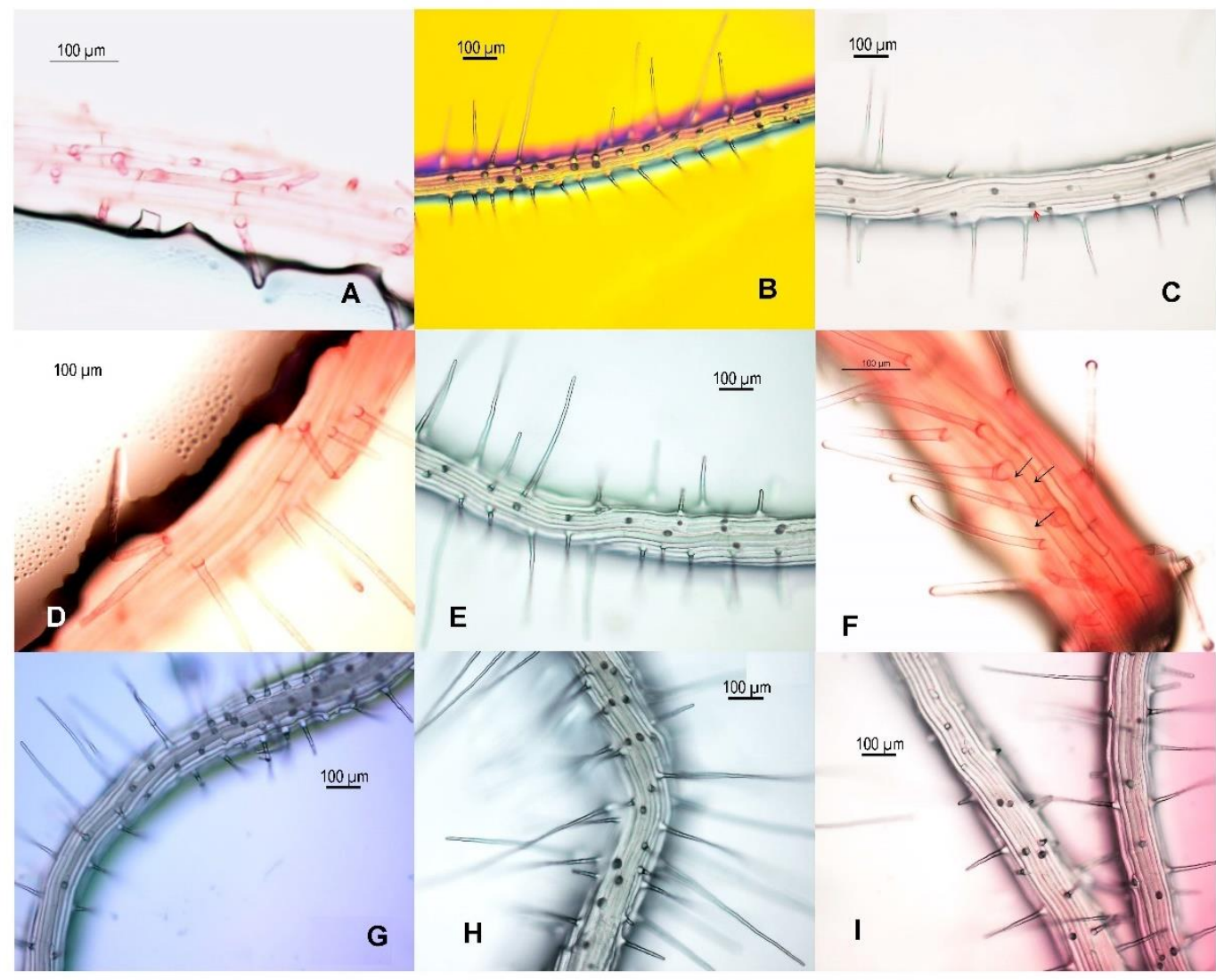

Figure 3B 
Iva MCCARTHY-SUÁREZ

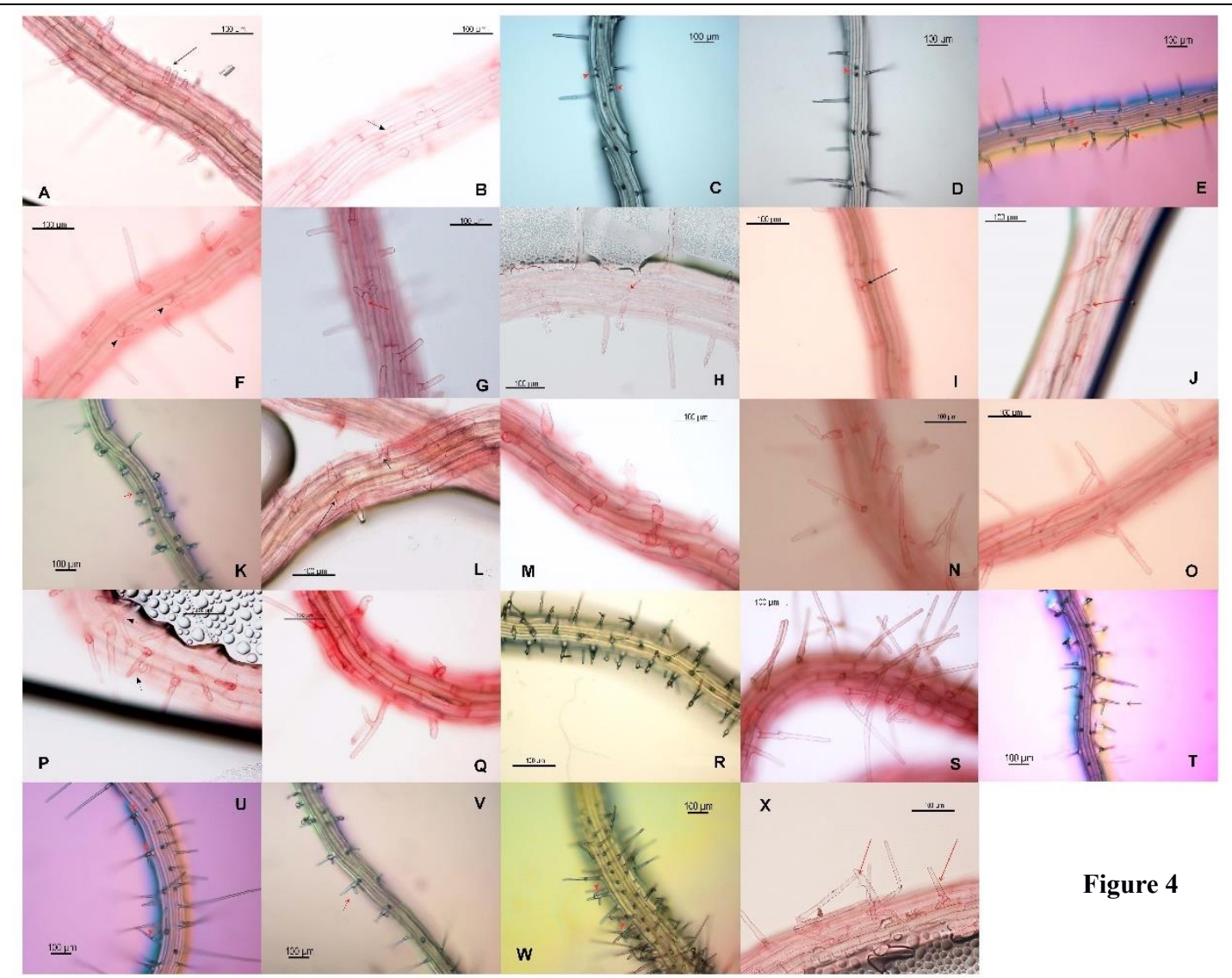


SUPRA-PHYSIOLOGICAL LEVELS OF GIBBERELLINS / DELLAS ALTER THE PATTERNING ...

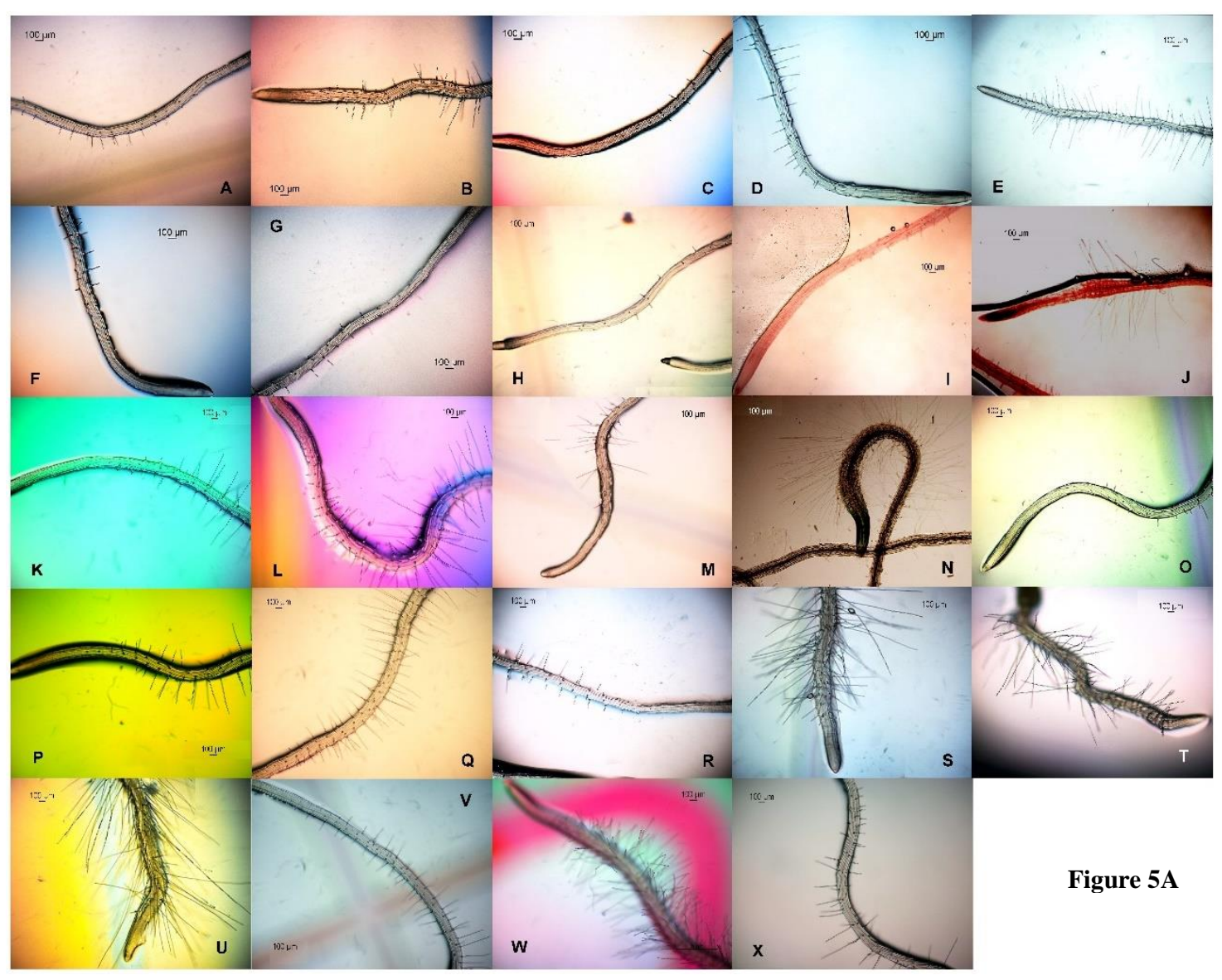


Iva MCCARTHY-SUÁREZ

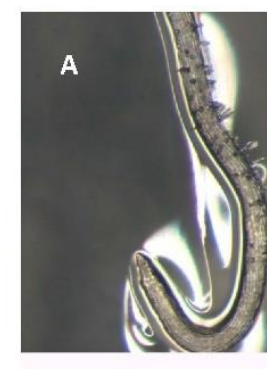

D

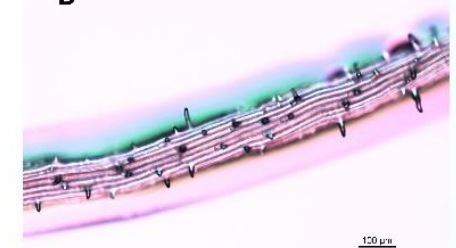

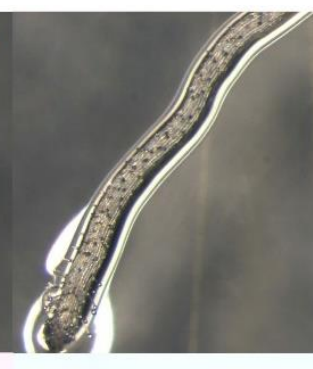

(n)

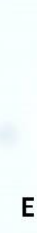

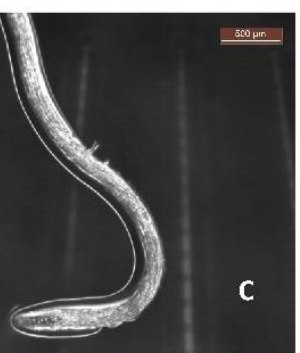

F

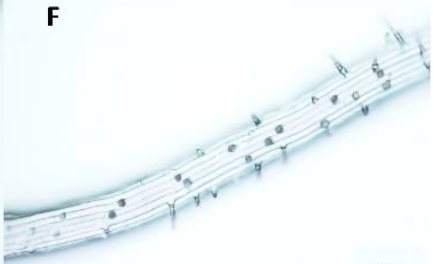

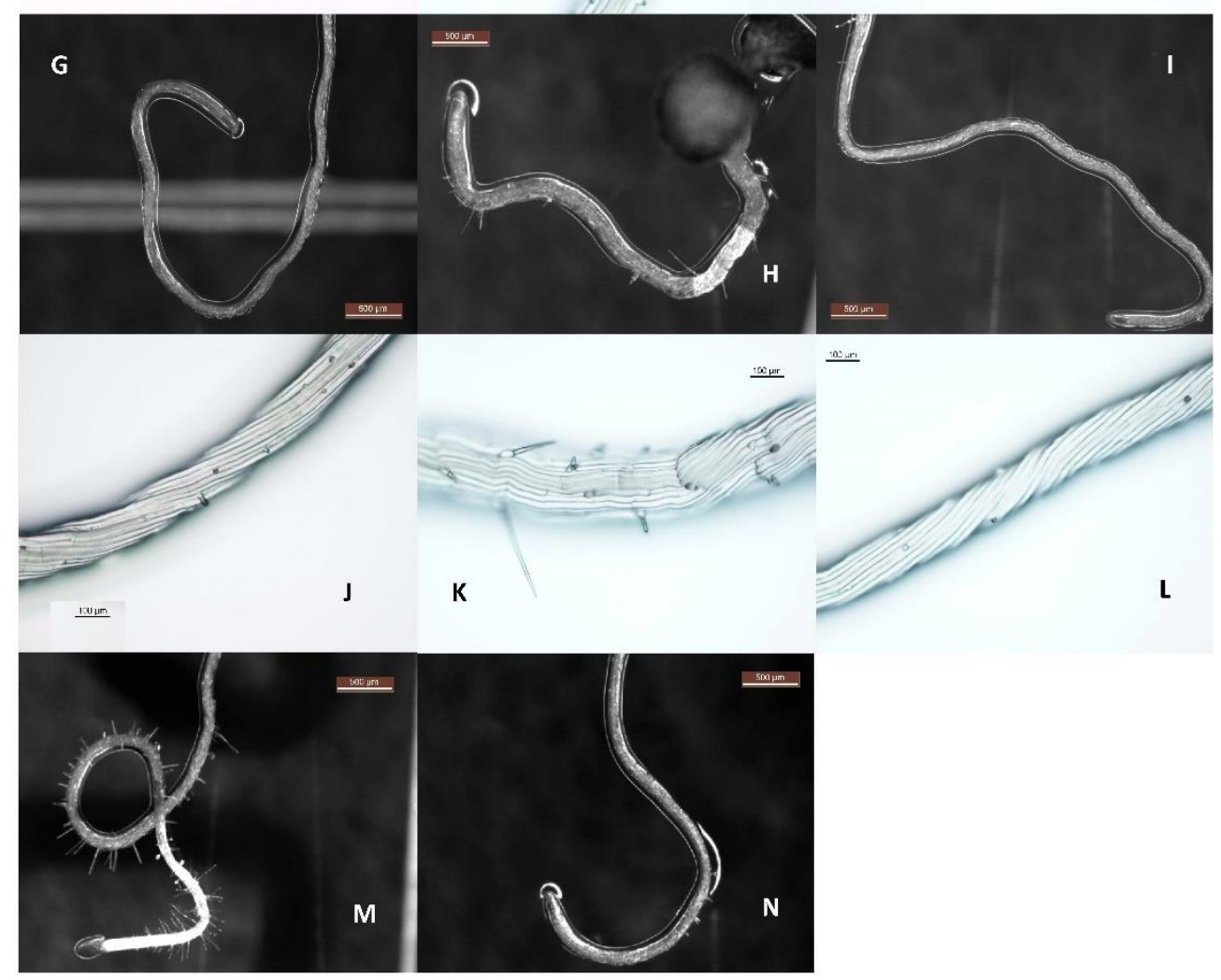

Figure 5B 


\section{Figure legends}

Figure 1A. Spatial gene expression of the root hair (*CPC) and non-hair (GL2, *EGL3, WER) epidermal cell fate markers in 5-day-old A. thaliana seedlings grown under (or harbouring) excessive levels of GAs/DELLAs. A) GL2pro::GUS (MS), 20X; B) GL2pro::GUS (0.5 $\mu$ M PAC), 0X; C) GL2pro::GUS (1 $\mu \mathrm{M}$ GA4), 20X; D) GL2pro::GUS (30 $\mu \mathrm{M}$ GA3), 20X; E) Ler x GL2pro::GUS (MS), 20X; F) gai-1 x GL2pro::GUS (MS), 20X; G) GID1b-ox x GL2pro::GUS (24 h in H2O; liquid incubation experiment; leaky line), 20X; H) GID1b-ox x GL2pro::GUS (24h in $1 \mu \mathrm{M}$ GA4; liquid incubation experiment), 20X; I) HSp::gai-1 x GL2pro::GUS (22 ${ }^{\circ} \mathrm{C}, 4$ h), 20X; J) HSp::gai-1 x GL2pro::GUS (37 ${ }^{\circ} \mathrm{C}, 4$ h), 20X; K) pGAI::gai-1:GR x GL2pro::GUS (24 h in MS; leaky line), 20X; L) pGAI::gai-1:GR x GL2pro::GUS (24h in $10 \mu \mathrm{M}$ DEXA), 20X; M) SCR::gai-1:GR x GL2pro::GUS (24h in MS; leaky line), 20X; N) SCR::gai1:GR x GL2pro::GUS (24h in $10 \mu \mathrm{M}$ DEXA), 20X; O) CPCpro::GUS (MS), 20X; P) CPCpro::GUS (0.5 $\mu \mathrm{M}$ PAC), 20X; Q) CPCpro::GUS (1 $\mu$ M GA4), 20X; R) EGL3pro::GUS (MS), 20X; S) EGL3pro::GUS (0.5 $\mu \mathrm{M}$ PAC), 20X; T) EGL3pro::GUS (1 $\mu \mathrm{M}$ GA4), 20X; U) WERpro::GFP (MS), 40X; V) WERpro::GFP (0.5 $\mu$ M PAC), 40X; W) WERpro::GFP (1 $\mu$ M GA4), 40X; X) ML1::gai-1 x GL2pro::GUS, $20 \mathrm{X}$. In control seedlings, GL2 is expressed in root non-hair (Atrichoblast) cells. *CPC protein is expressed in root non-hair cells, but migrates to root hair cells. ${ }^{*}$ EGL3 protein is expressed in root hair cells, but migrates to root non-hair cells. The scale bar represents $100 \mu \mathrm{m}(20 \mathrm{X})$ or $50 \mu \mathrm{m}(40 \mathrm{X})$.

Figure 1B. Spatial gene expression of the root non-hair epidermal cell fate marker GL2 in cross sections of resin-embedded roots of $A$. thaliana seedlings grown for 5 days under excessive levels of GAs/DELLAs. A) GL2pro::GUS (MS); B) GL2pro::GUS (0.5 $\mu$ M PAC): Lack of GL2 expression in an Atrichoblast cell; C) GL2pro::GUS (0.5 $\mu \mathrm{M}$ PAC): Ectopic expression of GL2 in a Trichoblast cell; D) GL2pro::GUS (1 $\mu$ M GA4): Ectopic expression of GL2 in a Trichoblast cell and lack of GL2 expression in an Atrichoblast cell; E) GL2pro::GUS (1 $\mu \mathrm{M}$ GA4): Lack of GL2 expression in an Atrichoblast cell; F) Ectopic root hair cell in gai-1. Magnification: 40X. The scale bar represents $50 \mu \mathrm{m}$.

Figure 2A. Ectopic root hairs and ectopic root non-hairs in root tips of 5-day-old A. thaliana seedlings grown under (or harbouring) excessive levels of GAs/DELLAs. A) Col(0) (MS) correct hair (epidermis); B) $\operatorname{Col}(0)(\mathrm{MS})$, correct hair (cortex); C) $\operatorname{Col}(0)(0.5 \mu \mathrm{M}$ PAC) ectopic hair (epidermis); D) $\operatorname{Col}(0)(0.5$ $\mu \mathrm{M}$ PAC) ectopic hair (cortex); E) Col(0) (1 $\mu \mathrm{M}$ GA4) ectopic hair (epidermis); F) Col(0) (1 $\mu$ M GA4) ectopic hair (cortex); G) $\operatorname{Col}(0)$ (MS) correct non-hair (epidermis); H) Col(0) (MS) correct non-hair (cortex); I) $\operatorname{Col}(0)(0.5 \mu \mathrm{M}$ PAC) ectopic non-hair (epidermis); J) $\operatorname{Col}(0)(0.5 \mu \mathrm{M}$ PAC) ectopic non-hair (cortex); K) $\operatorname{Col}(0)$ (1 $\mu \mathrm{M}$ GA4) ectopic non-hair (epidermis); L) Col(0) (1 $\mu \mathrm{M} \mathrm{GA4)} \mathrm{ectopic} \mathrm{non-hair}$ (cortex); M) Ler, correct hair and non-hair (epidermis); N) Ler, correct hair and non-hair (cortex); O) gai1, ectopic hair (epidermis); P) gai-1, ectopic hair (cortex); Q) QD, ectopic hair (epidermis); R) QD, ectopic hair (cortex); S) 5X, ectopic non-hair (epidermis); T) 5X, ectopic non-hair (cortex); U) pGAI::gai-1:GR (10 $\mu \mathrm{M}$ DEXA), ectopic non-hair and ectopic hair (epidermis); V) pGAI::gai-1:GR (10 $\mu$ M DEXA), ectopic non-hair and ectopic hair (cortex); W) HSp::gai-1, $2 \mathrm{~d}$ after heat shock $\left(37^{\circ} \mathrm{C}, 4 \mathrm{~h}\right)$, ectopic hair (epidermis); X) HSp::gai-1, 2d after heat-shock $\left(37^{\circ} \mathrm{C}, 4 \mathrm{~h}\right)$, ectopic hair (cortex). Magnification: $20 \mathrm{X}$. The scale bar represents $100 \mu \mathrm{m}$. Propidium iodide staining.

Figure 2B. Ectopic hairs and non-hairs in root tips of 5-day-old A. thaliana seedlings over-expressing the gai-1 DELLA in different tissues of the root. A) UAS::gai-1 x J2812, ectopic hairs (epidermis); B) UAS::gai1 x J2812, ectopic hairs (cortex); C) UAS::gai-1 x J2812 (ectopic non-hair, epidermis); D) UAS::gai-1 x J2812 (ectopic non-hair, cortex); E) UAS::gai-1 x Q2393 (ectopic hair, epidermis); F) UAS::gai-1 x Q2393 (ectopic hair, cortex); G) UAS::gai-1 x Q2393 (ectopic non-hair, epidermis); H) UAS::gai-1 x Q2393 (ectopic non-hair, cortex); I) UAS::gai-1 x Q2500 (ectopic hair, epidermis); J) UAS::gai-1 x Q2500 (ectopic hair, cortex); K) UAS::gai-1 x J0121 (ectopic non-hair, epidermis); L) UAS::gai-1 x J0121 (ectopic non-hair, cortex). Magnification: 20X. The scale bar represents $100 \mu \mathrm{m}$. Propidium iodide staining.

Figure 3A. Arrangement of root hairs in root tips of 5-day-old A. thaliana seedlings grown under (or harbouring) excessive levels of GAs/DELLAs. A) Col(0) (MS), 10X; B) Col(0) (0.5 $\mu$ M PAC), 10X; C) 
Col(0) (30 $\mu$ M GA3), 10X; D) Ler, 10X; E) gai-1, 10X; F) QD, 10X; G) 5X, 10X; H) GID1b-ox (MS, leaky line), lateral root, 10X; I) pGAI::gai-1:GR (30h in MS; leaky line), 10X; J) pGAI::gai-1:GR (30h in $10 \mu \mathrm{M}$ DEXA), 10X; K) SCR::gai-1:GR (72h in MS; leaky line), 10X; L) SCR::gai-1:GR (48h in $10 \mu \mathrm{M}$ DEXA), 10X; M) UAS::gai-1 x C24, 10X; N) UAS::gai-1 x J0951, 10X; O) UAS::gai-1 x J2812, 10X; P) UAS::gai-1 x N9142, 10X; Q) UAS::gai-1 x M0018, 10X; R) UAS::gai-1 x Q2500, 10X; S) UAS::gai-1 x Q2393, 10X; T) UAS::gai-1 x J0121, 10X; U) UAS::gai-1 x J0631, 10X; V) UAS::gai-1 x J0571, 10X; W) UAS::gai-1 x J3281, 4X; X) ML1::gai-1, 10X. The scale bar represents $100 \mu \mathrm{m}(10 \mathrm{X})$ or $500 \mu \mathrm{m}(4 \mathrm{X})$.

Figure 3B. Adjacent hair rows in root tips of 5-day-old A. thaliana seedlings grown under (or harbouring) excessive levels of GAs/DELLAs. A) Col(0) (0.5 $\mu \mathrm{M}$ PAC), 20X; B) gai-1 (lateral root), 10X; C) QD, 10X; D) HSp::gai-1, 2 days after heat shock $\left(37^{\circ} \mathrm{C}, 4 \mathrm{~h}\right), 20 \mathrm{X}$; E) pGAI::gai-1:GR (MS, leaky line), 10X; F) SCR::gai-1:GR (MS, leaky line), 20X; G) UAS::gai-1 x J2812, 10X; H) UAS::gai-1 x M0018, 10X; I) UAS::gai-1 x Q2393, 10X. The scale bar represents $100 \mu \mathrm{m}$.

Figure 4. Morphology of Trichoblasts and root hairs in root tips of 5-day-old A. thaliana seedlings grown under (or harbouring) excessive levels of GAs/DELLAs. A) Two-haired cell in PAC (0.5 $\mu \mathrm{M}), 20 \mathrm{X}$; B) Cell with two hair bulges in PAC $(0.5 \mu \mathrm{M}), 20 \mathrm{X}$; C) Two-haired cells in gai-1, 10X; D) Two-haired cells in QD, 10X; E) Two-haired cells and branched hairs in UAS::gai-1 x Q2393, 10X; F) Two-tipped hairs in PAC $(0.5 \mu \mathrm{M}), 20 X$; G) Two-tipped hairs in GA4 $(1 \mu \mathrm{M}), 20 \mathrm{X}$; H) Two-tipped hairs in gai-1, 20X; I) Twotipped hairs in QD, 20X; J) Two-tipped hairs in pGAI::gai-1:GR (10 $\mu$ M DEXA), 20X; K) Two-tipped hairs in UAS::gai-1 x J0121, 10X; L) Two-tipped and branched hairs in PAC (0.5 $\mu \mathrm{M}), 20 \mathrm{X}$; M) Branched hairs in PAC $(0.5 \mu \mathrm{M}), 20 \mathrm{X}$; N) Branched hairs in gai-1, 20X; O) Branched hairs in QD, 20X; P) Branched hairs in pGAI::gai-1:GR (10 $\mu \mathrm{M}$ DEXA), 20X; Q) Branched hairs in SCR::gai-1:GR (MS; leaky line), 20X; R) Branched hairs in UAS::gai-1 x J0951, 20X; S) Branched hairs in UAS::gai-1 x J2812, 20X; T) Branched hairs in UAS::gai-1 x N9142, 10X; U) Branched hairs in UAS::gai-1 x Q2393, 10X; V) Branched hairs in UAS::gai-1 x J0121, 10X; W) Branched hairs in UAS::gai-1 x J0631, 10X; X) Branched hairs in ML1::gai-1, 20X. The scale bar represents $100 \mu \mathrm{m}$.

Figure 5A. Length and abundance of root hairs in root tips of 5-day-old A. thaliana seedlings grown under (or harbouring) excessive levels of GAs/DELLAs. A) Col(0) (MS); B) $\operatorname{Col}(0)(0.5 \mu \mathrm{M} \mathrm{PAC})$; C) $\mathrm{Col}(0)$ (1 $\mu$ M GA4 ); D) Ler; E) gai-1; F) QD; G) 5X; H) GID1b-ox (MS; leaky line); I) HSp::gai-1 (24h at $22{ }^{\circ} \mathrm{C}$ ); J) HSp::gai-1 (24h after heat-shock $\left(37^{\circ} \mathrm{C}, 4 \mathrm{~h}\right)$ ); K) pGAI::gai-1:GR (30h in MS; leaky line); L) pGAI::gai-1:GR (30h in $10 \mu$ M DEXA); M) SCR::gai-1:GR (24h in MS; leaky line); N) SCR::gai-1:GR (24h in $10 \mu \mathrm{M}$ DEXA); O) UAS::gai-1 x C24; P) UAS::gai-1 x J0951; Q) UAS::gai-1 x J2812; R) UAS::gai-1 x N9142; S) UAS::gai-1 x M0018; T) UAS::gai-1 x J0571; U) UAS::gai-1 x Q2500; V) UAS::gai-1 x Q2393; W) UAS::gai-1 x J0631; X) UAS::gai-1 x J0121. Magnification: 4X. The scale bar represents $100 \mu \mathrm{m}$.

Figure 5B. Length and abundance of root hairs in root tips of wer, cpc and 35S::CPC mutant seedlings grown for 5 days under excessive levels of GAs/DELLAs. A) wer mutant (MS), lens; B) wer mutant (0.5 $\mu \mathrm{M}$ PAC), lens; C) wer mutant (1 $\mu \mathrm{M}$ GA4), lens; D) wer mutant (MS), microscope; E) wer mutant (0.5 $\mu \mathrm{M}$ PAC), microscope; F) wer mutant ( $1 \mu \mathrm{M}$ GA4), microscope; G) cpc mutant (MS), lens; H) cpc mutant (0.5 $\mu \mathrm{M}$ PAC), lens; I) cpc mutant (1 $\mu \mathrm{M}$ GA4), lens; J) cpc mutant (MS), microscope; K) cpc mutant (0.5 $\mu \mathrm{M}$ PAC), microscope; L) cpc mutant (1 $\mu \mathrm{M}$ GA4), microscope; M) 35S::CPC mutant (MS), lens; N) 35S::CPC mutant (1 $\mu \mathrm{M}$ GA4), lens. Magnification: $2.5 \mathrm{X}$ (lens) or 10X (microscope). The scale bar represents $500 \mu \mathrm{m}$ (lens) or $100 \mu \mathrm{m}$ (microscope).

\section{Discussion}

The GAs/DELLAs might regulate the root hair patterning in A. thaliana seedlings

Whereas the role of GAs/DELLAs in the production and distribution of leaf hairs has been well studied [TELFER \& al. 1997; PERAZZA \& al. 1998], their hypothetical function in the determination and arrangement of root hairs has not been examined up to date. To this aim, 
the effects of high levels of GAs/DELLAs on the spatial gene expression of the hair (CPC) and non-hair (GL2, WER and EGL3) markers of root epidermal cell fate, as well as on the distribution of root hairs, were analysed in seedlings of A. thaliana. Results showed that excessive levels of GAs/DELLAs impaired the spatial gene expression of the root hair/non-hair epidermal cell fate markers and disarranged the normal distribution of root hairs, what suggested that the GAs/DELLAs might be involved in regulating the root hair patterning in seedlings of A. thaliana. In fact, stable or inducible mutants with low (gai-1, HSp::gai-1, pGAI::gai-1:GR, $S C R:: g a i-1: G R)$ or high $(Q D, 5 X, G I D 1 b-o x)$ levels of GAs showed not only a random expression of GL2 at the MZ and EZ of the root, known as the cell fate-decision zones [PERNAS $\&$ al. 2010], but also a disarrangement of the root hairs. Because neither the spatial expression of GL2 nor the distribution of root hairs suffered changes when the gai-1 DELLA was overexpressed at the root epidermis (ML1::gai-1 x GL2pro::GUS, ML1::gai-1 and UAS::gai-1 $\mathrm{x}$ J0951 transgenic lines), it was concluded that the GAs/DELLAs do not seem to affect the root hair patterning in A. thaliana seedlings by acting on this root cell layer, but on tissues placed underneath. In fact, over-expression of gai-1 at the cortex, endodermis or pericycle of the root $\mathrm{MZ}$ altered the root hair patterning.

Interestingly, expressing $C P C$ at the stele rescues the phenotype of the hairless mutant $c p c$, what suggests that epidermal cell differentiation might be controlled from the internal tissues of the root [RISHMAWI \& al. 2014]. Therefore, the results of this study suggest that, as it was previously reported for auxins, ET, ABA, NO, BRs and SLs [SCHIEFELBEIN, 2003], the GAs/DELLAs might regulate the root hair patterning in seedlings of $A$. thaliana independently from the gene network for the specification of root epidermal cell fate, although confirmatory studies might be required.

The reason why excessive levels of GAs/DELLAs disarranged the root hair patterning in seedlings of $A$. thaliana might have been, in part, related to their effects on the cytoskeleton of MT. The MT cytoskeleton, consisting in polymers of $\alpha$ and $\beta$ tubulin, is essential for the appropriate distribution of positional signals during development [SCHIEFELBEIN, 2003]. Also, the orientation of MT participates in the determination of epidermal cell fate [PIETRA, 2014]. Thus, MT lay randomly in Trichoblasts but transversally in Atrichoblasts [DUGARDEYN \& VAN DER STRAETEN, 2008]. Hormone-induced reorganization of MT is also necessary for root hair initiation [BAO \& al. 2001; SCHIEFELBEIN, 2003]. Interestingly, the GAs/DELLAs regulate MT organization by interacting with prefoldin, a protein required for the folding of tubulin [LOCASCIO \& al. 2013]. As a result of this interaction, MT are organized in the presence of GAs, like in root or mesocotyl epidermal cells, and disorganized in the presence of DELLAs [PERAZZA \& al. 1998; BOUQUIN \& al. 2003; LOCASCIO \& al. 2013]. On the other hand, mutants impaired in MT assembly have an altered root hair patterning [BOUQUIN \& al. 2003]. The luel mutant, which lacks a MT-severing and cell wall (CW) biosynthesis-related katanin protein, and whose MT are disorganized, is allelic to ectopic root hair 1 (erhl) and has an altered root hair patterning [BOUQUIN \& al. 2003; WEBB \& al. 2002]. In addition, lue 1 presents an inappropriate regulation of the GA biosynthesis-related AtGA20ox activity and responds to GAs [SCHNEIDER \& al. 1997; BOUQUIN \& al. 2003].

Ectopic root hairs have also been described in TUA6/AS transgenic lines underexpressing $\alpha$-tubulin genes, in plants treated with MT polymerization-inhibiting drugs or with trichostatin A (TSA, a histone deacetylase (HDA) inhibitor), during the inducible expression of MT-interacting phospholipase-D (PLD) activity, as well as in mutants of MT severing/reorganization-related proteins, such as HDA, COBRA, SABRE and katanin p60 [SCHIEFELBEIN \& al. 1997; BAO \& al. 2001; BOUQUIN \& al. 2003; SEDBROOK, 2004; 
Iva MCCARTHY-SUÁREZ

WANG, 2005; XU \& al. 2005; LI \& al. 2006, 2015; CHEN \& al. 2015; PIETRA \& al. 2015]. In fact, the katanin complex is required for the specification of root epidermal cells [WEBB \& al. 2002]. In addition, the katanin P60-related alteration of MT organisation affects the composition and deposition of the CW [SEDBROOK, 2004]. Histone deacetylation also participates in cellular patterning, because TSA-induced histone acetylation modifies GL2, WER and CPC expression and localization and induces ectopic root hairs [XU \& al. 2005; CUI \& BENFEY, 2009]. Lack of SABRE function equally destabilizes the expression of cell fate markers, including WER and GL2 [PIETRA \& al. 2015]. In addition, a delocalized expression of GL2 has been documented for the $j k d$ (jackdaw) and $s c m$ (scrambled) mutants [HASSAN \& al. 2010; PIETRA, 2014].

Therefore, the MT participate in cell identity specification [WEBB \& al. 2002]. Cell identity, in turn, mediates the root responses to abiotic stress [DINNENY \& al. 2008]. Thus, ectopic root hairs and non-hairs have been described in A. thaliana seedlings exposed to gamma irradiation, $\mathrm{Cd}$ or As, and during $\mathrm{P}$ deficiency, although without quantitative changes in the WER and GL2 expression [MA \& al. 2001; NAGATA \& al. 2004; YANG \& al. 2007; BAHMANI \& al. 2016]. Moreover, stress down-regulates actin and tubulin gene expression [SÁNCHEZ-CALDERÓN \& al. 2013]. In turn, a reduced expression of the $\alpha$-tubulin gene results in MT disassembly, with MT laying in an aberrant way, and in their reorganization [BAO $\&$ al. 2001].

Consequently, the root hair patterning responds to environmental signals [SALAZARHENAO \& al. 2016]. For instance, the photoperiod and thermoperiod control the root hair patterning in tomato [TSAI \& al. 2004]. Interestingly, the GAs participate in thermotolerance [ALONSO-RAMÍREZ \& al. 2009]. Thus, the results of this study suggest that the GAs/DELLAs might regulate, in part, the root hair patterning in A. thaliana seedlings by altering MT organization. In root cells, excessive levels of DELLAs might disorganize the cytoskeleton of MT, thereby impairing the link between positional signals and cell fate, whereas excessive levels of GAs might stabilize it.

Results of this study also point at a possible role for the DELLAs in regulating the root hair patterning in response to nutritional deficiencies. The random disposition of root hairs under excessive levels of DELLAs might favour the foraging of scarce or non-mobile minerals in deficient soils. Thus, altering the root hair patterning by modulating the levels of GAs/DELLAs might constitute a mechanism used by plants for increasing the possibilities of acquiring nonavailable minerals, such as $\mathrm{P}$ or Fe, in deficient soils. In fact, plant deficiencies in $\mathrm{P}, \mathrm{B}$ or $\mathrm{Fe}$ disarrange the root hair patterning and induce ectopic root hairs [SCHMIDT \& al. 2000; PÉRET $\&$ al. 2011; JANES \& al. 2018]. Moreover, low availability of P increases the levels of DELLAs and reduces the levels of GAs in roots [JIANG \& al. 2007].

Results of this study also suggest that the GAs/DELLAs might affect the root hair patterning in A. thaliana seedlings by acting not at the epidermis, where the gene network for the root hair/non-hair epidermal cell fate operates, but at tissues placed underneath (cortex, endodermis and pericycle). However, confirmatory studies are still needed to uncover why the epidermal expression of gai- 1 did not modify the root hair patterning in A. thaliana seedlings, in spite that the DELLAs promote the disorganization of MT in root epidermal cells. Moreover, the fact that only one DELLA (gai-1) was over-expressed in this study, and that expression of gai-1 at the epidermis (ML1::gai-1, J0951 > gai-1) induced longer and branched root hairs, suggests that the effects of the GAs/DELLAs on the root epidermal cells and/or the root hair patterning in seedlings of $A$. thaliana might be different depending on the particular concentration at which these hormones might be present. 
The GAs/DELLAs might regulate the shape, length and abundance of root hairs in root tips of $A$. thaliana seedlings

Supra-physiological levels of GAs/DELLAs in A. thaliana seedlings also induced twohaired root epidermal cells, two-tipped root hairs and branched root hairs. Multiple hairs per root epidermal cell, two-tipped root hairs and branched root hairs have also been reported in the SUPERCENTIPEDE (scnl) mutant, with supernumerary root hair initiation sites, in TUA6/AS A. thaliana transgenic lines under-expressing $\alpha$-tubulin genes, in root hair defective 3, 4 and 6 (rhd3, rhd4, rhd6) and PLD mutants, in plants treated with MT-depolymerizing oryzalin, MTdisorganizing 1-butanol (a PLD-inhibitor) or MT-stabilizing Taxol, in ROP2 (proteins controlling MT organization) over-expressing plants, and in plants subjected to $\mathrm{Fe}$ or $\mathrm{NO}_{3}{ }^{-}$ deficiency [SCHIEFELBEIN \& SOMERVILLE, 1990; SCHIEFELBEIN \& al. 1993; MASUCCI \& SCHIEFELBEIN, 1994; GILROY \& JONES, 2000; SCHMIDT \& al. 2000; BAO \& al. 2001; FOREMAN \& DOLAN, 2001; GRIERSON \& SCHIEFELBEIN, 2002; JONES \& al. 2002; GARDINER \& al. 2003; MÜLLER \& SCHMIDT, 2004; CAROL \& DOLAN, 2006; ISHIDA \& al. 2008; SHIN \& al. 2011; PIETRA, 2014]. Interestingly, hormone-induced reorganization of MT is required for the morphogenesis of root hairs [BAO \& al. 2001; SCHIEFELBEIN, 2003]. In turn, the phenotype of root hair branching, due to changes in actin distribution and dynamics, has been related to the induction of genes for GA biosynthesis and $\mathrm{CW}$ modification, and reported during legume-rhizobium symbiosis (i.e., soybean infected with Bradyrhyzobium japonicum), in plants treated with MT-inhibiting drugs, and in mutants of genes necessary for a correct growth of root hairs, such as TIPl (involved in the biosynthesis of CW components and probably in the arrangement of actin filaments) and RHD3 [SCHIEFELBEIN \& SOMERVILLE, 1990; SCHIEFELBEIN \& al. 1993; BAO \& al. 2001; SALAZAR-HENAO \& al. 2016].

The disruption of MT also affects trichome branching [GILROY \& JONES, 2000], as actin regulates the shape and growth of trichomes [RODRÍGUEZ-SERRANO \& al. 2014]. In addition, the GAs promote trichome branching and influence CW growth [TELFER \& al. 1997; PERAZZA \& al. 1998]. Thus, the spy5 mutant (with high levels of GAs and which also displays ectopic root hairs) has over-branched trichomes [PERAZZA \& al. 1998; MUTANWAD \& al. 2020]. On the other hand, during trichome development, the number of branches and the level of endo-reduplication, which is induced by GAs, are closely related [PERAZZA \& al. 1998; KONDOROSI \& al. 2001].

In this study, excessive levels of DELLAs in A. thaliana seedlings also induced longer root hairs near the root tip. Interestingly, nutrient availability prevents root hair elongation [TSAI \& al. 2004], whereas deficiencies in P, B or Mg induce root hair elongation, being the higher levels of DELLAs the mediators of the extra-elongation of root hairs [PÉRET \& al. 2011; LIU \& al. 2018]. Elongated root hairs have also been described in plants exposed to gamma irradiation, Cd or As, as well as in polyploids [NAGATA \& al. 2004; SETTER \& al. 2015; BAHMANI \& al. 2016; SALAZAR-HENAO \& al. 2016]. Conversely, shorter root hairs have been reported in mutants of the TIP1, PLD 1 1-PLD $\zeta 2$, and RSLA (a component of GAs signalling) genes [SCHIEFELBEIN \& al. 1993; LI \& al. 2006; PÉRET \& al. 2011]. Moreover, the GAs are necessary for root hair elongation, as the ga 1-3 mutant (deficient in GAs) produces shorter root hairs [PÉRET \& al. 2011]. However, the GAs might act at a later stage of root hair development, as apparently, in this study, high levels of GAs did not stimulate root hair elongation near the root tip as much as the high levels of DELLAs did. Therefore, the changes induced, in this study, by excessive levels of GAs/DELLAs on the shape and length of root hairs 
in seedlings of A. thaliana might have been related to the effect of these hormones on the MT cytoskeleton and/or the $\mathrm{CW}$ biosynthesis of the root epidermal cells.

Regarding root hair abundance, it is known that nutrient availability inhibits root hair production [TSAI \& al. 2004]. Excess of $\mathrm{Na}^{+}$reduces root hair abundance [DINNENY \& al. 2008], whereas deficiencies in P, Fe or B increase the frequency of root hairs, mainly by inducing ectopic root hair cells [SCHIEFELBEIN, 2003; MARTÍN-REJANO \& al. 2011; PÉRET \& al. 2011; SHIN \& al. 2011; SALAZAR-HENAO \& al. 2016; JANES \& al. 2018]. An increased density of root hairs has also been reported in ROP2 over-expressing plants, in arm (ctll; cellulose biosynthesis-related) and sabre mutants, in plants exposed to $\mathrm{Cd}, \mathrm{V}$ or As, and in polyploids [JONES \& al. 2002; PIETRA, 2014; LIN \& al. 2015; BAHMANI \& al. 2016; SALAZAR-HENAO \& al. 2016]. Interestingly, the levels of GAs determine trichome number [PERAZZA \& al. 1998]. In turn, HDA19 controls the response of the root hair density to low P [CHEN \& al. 2015].

Because of the GAs/DELLAs are involved in plant stress responses [ALONSORAMÍREZ \& al. 2009], the results of this study suggest that these hormones might have a role in regulating the response of the root hair abundance to nutrient availability. In fact, in this study, root hairs near the root tip were denser and longer under excessive DELLAs, but scarcer and shorter under excessive GAs. With this respect, it is known that root hairs grow closer to the root MZ under mechanic stress or B deficiency [OKAMOTO \& al. 2008; MARTÍN-REJANO $\&$ al. 2011]. Also, the abundance and length of root hairs respond to environmental signals [SALAZAR-HENAO \& al. 2016]. Light signalling, for instance, influences root hair length [GRIERSON \& SCHIEFELBEIN, 2002]. In turn, the photo-period conditions affect the biosynthesis and/or sensibility of GAs [TELFER \& al. 1997].

As PLD inhibitors break the organization of MT, which is essential for the correct directionality, elongation and morphology of root hairs [GARDINER \& al. 2003], then, the morphological alterations of root hairs observed in this study point to a possible impairment, by excessive levels of GAs/DELLAs, of the actin microfilaments, the cytoskeleton of MT, and the ROP GTPase proteins. In fact, hair cell morphogenesis requires $\alpha$-tubulin and Rho-like GTPase activity, which, in turn, interacts with katanin P60 to promote MT ordering [FOREMAN \& DOLAN, 2001; LIN \& al. 2013]. Moreover, the SABRE protein (involved in MT organisation and the stabilization of epidermal patterning factors) acts upstream of ROPs [PIETRA, 2014].

\section{Conclusions}

The results from this study suggest that the GAs/DELLAs might regulate the patterning, shape and abundance of root hairs in root tips of A. thaliana seedlings, and that they might do it by acting from the sub-epidermal tissues of the root. In fact, growth of $A$. thaliana seedlings under supra-physiological levels of GAs/DELLAs altered the distribution, morphology and frequency of root hairs.

\section{Notes on contributor}

Iva MCCARTHY-SUÁREZ - is a postdoctoral researcher in plant biology with special interest in the mechanism of action of plant hormones, senescence and environmental stress. 


\section{Acknowledgements}

Special thanks to Dr. Miguel Ángel Blázquez and Dr. David Alabadí for supporting the writing of this paper. This study was performed at the Blázquez-Alabadí laboratory (Hormone Signalling and Plant Plasticity Group) of the Instituto de Biología Celular y Molecular de Plantas (IBMCP)-UPV-CSIC, Valencia, Spain. Thanks also to Dr. Benedicte Desvoyes for the training in the hair/non-hair cell counting (Dr. Crisanto Gutiérrez Lab). I. McCarthy-Suárez also acknowledges a JAE-Doc postdoctoral fellowship (2008-2011, C.S.I.C., Valencia, Spain). This paper is dedicated to the loving memory of Dr. Francisco Culiáñez-Macià, Principal Investigator at the IBMCP-UPV-CSIC, Valencia, Spain.

\section{References}

ALONSO-RAMÍREZ A., RODRÍGUEZ D., REYES D., JIMÉNEZ J. A., NICOLÁS G., LÓPEZ-CLIMENT M., GÓMEZ-CÁRDENAS A. \& NICOLÁS C. 2009. Evidence for a role of gibberellins in salicylic acidmodulated early plant responses to abiotic stress in Arabidopsis seeds. Plant Physiology. 150(3): 1335-1344. https://doi.org/10.1104/pp.109.139352

BAHMANI R., KIM D. G., KIM J. A. \& HWANG S. 2016. The density and length of root hairs are enhanced in response to cadmium and arsenic by modulating gene expressions involved in fate determination and morphogenesis of root hairs in Arabidopsis. Frontiers in Plant Science. 7: 1-16. https://doi.org/10.3389/fpls.2016.01763

BAO Y., KOST B. \& CHUA N. H. 2001. Reduced expression of $\alpha$-tubulin genes in Arabidopsis thaliana specifically affects root growth and morphology, root hair development and root gravitropism. Plant Journal. 28(2): 145-157. https://doi.org/10.1046/j.1365-313x.2001.01142.x

BOUQUIN T., MATTSON O., NAESTED H., FOSTER R. \& MUNDY J. 2003. The Arabidopsis lue1 mutant defines a katanin 660 ortholog involved in hormonal control of microtubule orientation during cell growth. Journal of Cell Science. 116(Pt 5): 791-801. https://doi.org/10.1242/jcs.00274

CAO X. F., LINSTEAD P., BERGER F., KIEBER J. \& DOLAN L. 1999. Differential ethylene sensitivity of epidermal cells is involved in the establishment of cell pattern in the Arabidopsis root. Physiologiae Plantarum. 106(3): 311-317. https://doi.org/10.1034/j.1399-3054.1999.106308.x

CAROL R. J. \& DOLAN L. 2006. The roles of reactive oxygen species in cell growth: Lessons from root hairs. Journal of Experimental Botany. 57(8): 1829-1834. https://doi.org/10.1093/jxb/erj201

CHEN C. Y., WU K. \& SCHMIDT W. 2015. The histone deacetylase HDA19 controls root cell elongation and modulates a subset of phosphate starvation responses in Arabidopsis. Science Reports. 5(1): 15708. https://doi.org/10.1038/srep15708

CHIEN J. C. \& SUSSEX I. M. 1996. Differential regulation of trichome formation on the adaxial and abaxial surfaces by gibberellins and photoperiod in Arabidopsis thaliana (L.) Heynh. Plant Physiology. 111(4): 1321-1328. https://doi.org/10.1104/pp.111.4.1321

CUI H. \& BENFEY P. 2009. Interplay between scarecrow, GA and like heterochromatin protein 1 in ground tissue patterning in the Arabidopsis root. Plant Journal. 58(6): 1016-1027. https://doi.org/10.1111/j.1365313X.2009.03839.x

DINNENY J. R., LONG T. A., WANG J. Y., JUNG J. W., MACE D., POINTER S., BARRON C., BRADY S. M., SCHIEFELBEIN J. \& BENFEY P. N. 2008. Cell identity mediates the responses of Arabidopsis roots to abiotic stress. Science. 320(5878): 942-945. https://doi.org/10.1126/science.1153795

DUGARDEYN J. \& VAN DER STRAETEN D. 2008. Ethylene: Fine tuning plant growth and development by stimulation and inhibition of elongation. Plant Science. 175(1-2): 59-70. https://doi.org/10.1016/jplantsci.2008.02.003

FOREMAN J. \& DOLAN L. 2001. Root hairs as a model system for studying plant cell growth. Annals of Botany. 88(1): 1-7. https://doi.org/10.1006/anbo.2001.1430

FRIGERIO M., ALABADÍ D., PÉREZ-GÓMEZ J., GARCÍA-CÁRCEL L., PHILliPS A. L., HEDDEN P. \& BLÁZQUEZ M. A. 2006. Transcriptional regulation of gibberellin metabolism genes by auxin signalling in Arabidopsis. Plant Physiology. 142(2): 553-563. https://doi.org/10.1104/pp.106.084871

GARDINER J., COLLINGS D. A., HARPER J. D. I. \& MARC J. 2003. The effects of the phospholipase D-antagonist 1-butanol on seedlings development and microtubule organisation in Arabidopsis. Plant Cell Physiology. 44(7): 687-696. https://doi.org/10.1093/pcp/pcg095

GILROY S. \& JONES D. L. 2000. Through form to function: Root hair development and nutrient uptake. Trends in Plant Science. 5(2): 56-60. https://doi.org/10.1016/S1360-1385(99)01551-4

GRIERSON C. \& SCHIEFELBEIN J. 2002. Root hairs. p. 2-22. In: SOMERVILLE C. R. \& MEYEROWITZ E. M. (eds.). The Arabidopsis book. American Society of Plant Biologists. Rockville, MD. 
HASSAN H., SCHERES B. \& BLILOU I. 2010. Jackdaw controls epidermal patterning in the Arabidopsis root meristem through a non-cell autonomous mechanism. Development. 137(9): 1523-1529. https://doi.org/10.1242/dev.048777

ISHIDA T., KURATA T., OKADA K. \& WADA T. 2008. A genetic regulatory network in the development of trichomes and root hairs. Annual Review in Plant Biology. 59: 365-386. https://doi.org/10.1146/annurev.arplant.59.032607.092949

JANES G., VON WANGENHEIM D., COWLING S., KERR I., BAND L., FRENCH A. P. \& BISHOP A. 2018. Cellular patterning of Arabidopsis roots under low phosphate conditions. Frontiers in Plant Science. 9: 735. https://doi.org/10.3389/fpls.2018.00735

JIANG C., GAO X., LIAO L., HARBERD N. P. \& FU X. 2007. Phosphate starvation, root architecture and anthocyanin accumulation responses are modulated by the gibberellin-DELLA signalling pathway in Arabidopsis. Plant Physiology. 145(4): 1460-1470. https://doi.org/10.1104/pp.107.103788

JONES M. A., SHEN J. J., FU Y., LI H., YANG Z., GRIERSON C. S. 2002. The Arabidopsis ROP2 GTPases is a positive regulator of root hair initiation and tip growth. Plant Cell. 14(4): 763-776. https://doi.org/10.1105/tpc.010359

KAPPUSAMY K. T., CHEN A. Y. \& NEMHAUSER J. L. 2009. Steroids are required for epidermal cell fate establishment in Arabidopsis roots. Proceedings of the National Academy of Sciences. 106(19): 8073-8076. https://doi.org/10.1073/pnas.0811633106

KONDOROSI E., ROUDIERA F. \& GENDREAU E. 2001. Plant cell size control: growing by ploidy? Current Opinion in Plant Biology. 3(6): 488-492. https://doi.org/10.1016/s1369-5266(00)00118-7

LEE M. M. \& SCHIEFELBEIN J. 1999. WEREWOLF, a MYB-related protein in Arabidopsis, is a position dependent regulator of epidermal cell patterning. Cell. 99: 473-483. https://doi.org/10.1016/S0092-8674(00)81536-6

LI M., QIN C., WELTI R. \& WANG X. 2006. Double knockouts of phospholipase D $\zeta 1$ and D 22 in Arabidopsis affect root elongation during phosphate-limited growth but do not affect root hair patterning. Plant Physiology. 140(2): 761-770. https://doi.org/10.1104/pp.105.070995

LI D. X., CHEN W. Q., XU Z. H. \& BAI S. N. 2015. Histone deacetylase 6-defective mutants show increased expression and acetylation of enhancer of tryptychon and caprice1 and glabra2 with small but significant effects on root epidermis cellular pattern. Plant Physiology. 168(4): 1448-1458. https://doi.org/10.1104/pp.15.00821

LIN D., CAO L., ZHOU Z., ZHU L., EHRHARDT D., YANG Z. \& FU Y. 2013. Rho GTPase signalling activates microtubule severing to promote microtubule ordering in Arabidopsis. Current Biology. 23(4): 290 - 297. https://doi.org/10.1016/j.cub.2013.01.022

LIN C. Y., HUANG L. Y., CHI W. C., HUANG T. L., KAKIMOTO T., TSAI C. R. \& HUANG H. J. 2015. Pathways involved in vanadate-induced root hair formation in Arabidopsis. Physiologiae Plantarum. 153(1): 137-148. https://doi.org/10.1111/ppl.12229

LIU M., BI J. \& JIN C. 2018. Developmental responses of root hairs to Mg deficiency. Plant Signal and Behaviour. 13(9): e1500068. https://doi.org/10.1080/15592324.2018.1500068

LOCASCIO A., BLÁZQUEZ M. A. \& ALABADÍ D. 2013. Dynamic regulation of cortical microtubule organization through prefoldin-DELLA interaction. Current Biology. 23(9): 804-809. https://doi.org/10.1016/j.cub.2013.03.053

LOMBARDO M. C., GRAZIANO M., POLACCO J. C. \& LAMATTINA L. 2006. Nitric oxide functions as a positive regulator of root hair development. Plant, Signalling and Behaviour. 1(1): 28-33. https://doi.org/10.4161/psb.1.1.2398

MA Z., BIELENBERG G. D., BROWN K. M. LYNCH J. P. 2001. Regulation of root hair density of phosphorus availability in Arabidopsis thaliana. Plant, Cell \& Environment. 24(4): 459-467. https://doi.org/10.1046/j.1365-3040.2001.00695.x

MARTÍN-REJANO E. M., CAMACHO-CRISTÓBAL J. J., HERRERA-RODRÍGUEZ M. B., REXACH J., NAVARRO-GOCHICOA M. T., GONZÁLEZ-FONTES A. 2011. Auxin and ethylene are involved in the responses of root system architecture to low boron supply in Arabidopsis seedlings. Physiologiae Plantarum. 142(2): 170- 178. https://doi.org/10.1111/j.1399-3054.2011.01459.x

MASUCCI J. D. \& SCHIEFELBEIN J. W. 1994 The RHD6 mutation of Arabidopsis thaliana alters root hair initiation through an auxin- and ethylene-associated process. Plant Physiology. 106(4): 1335-1346. https://doi.org/10.1104/pp.106.4.1335

MÜLLER M. \& SCHMIDT W. 2004. Environmentally induced plasticity of root hair development in Arabidopsis. Plant Physiology. 134(1): 409-419. https://doi.org/10.1104/pp.103.029066

MUTANWAD K. V., ZANGL I. \& LUCYSHYN D. 2020. The Arabidopsis O-fucosyltransferase SPINDLY regulates root hair patterning independently of gibberellin signalling. Development. 147(19): dev192039. https://doi.org/10.1242/dev.192039 
NAGATA T., TODORIKI S. \& KIKUCHI S. 2004. Radial expansion of root cells and elongation of root hairs of Arabidopsis thaliana induced by massive doses of gamma irradiation. Plant Cell Physiology. 45(11): 1557 1565. https://doi.org/10.1093/pcp/pch178

NIU Y., JIN C., JIN G., ZHOU Q., LIN X., TANG C. \& ZHANG Y. 2011. Auxin modulates the enhanced development of root hairs in Arabidopsis thaliana (L.) Heyhn. under elevated $\mathrm{CO}(2)$. Plant, Cell \& Environment. 34(8): 1304-1317. https://doi.org/10.1111/j.1365-3040.2011.02330.x

OKAMOTO T., TSURUMI S., SHIBASAKI K., OBANA Y., TAKAJI H., OONO Y. \& RAHMAN A. 2008. Genetic dissection of hormonal responses in the roots of Arabidopsis grown under continuous mechanical impedance. Plant Physiology. 146(4): 1651-1662. https://doi.org/10.1104/pp.107.115519

PERAZZA D., VACHON G. \& HERZOG M. 1998. Gibberellins promote trichome formation by up-regulating GLABROUS1 in Arabidopsis. Plant Physiology. 117(2): 375-383. https://doi.org/10.1104/pp.117.2.375

PÉRET B., CLÉMENT M., NUSSAUME L. \& DESNOS T. 2011. Root developmental adaptation to phosphate starvation: Better safe than sorry. Trends in Plant Science. 16(8): 442-450. https://doi.org/10.1016/j.tplants.2011.05.006

PERNAS M., RYAN E. \& DOLAN L. 2010. Schizoriza controls tissue system complexity in plants. Current Biology. 20(9): 812-823. https://doi.org/10.1016/j.cub.2010.02.062

PIETRA S. 2014. Characterization of new players in planar polarity establishment in Arabidopsis. PhD thesis. Umea Plant Science Centre Fysiologisk Botanik, Sweden.

PIETRA S., LANG P. \& GREBE M. 2015. SABRE is required for stabilization of root hair patterning in Arabidopsis thaliana. Physiologiae Plantarum. 153(3): 440-453. https://doi.org/10.1111/ppl.12257

RISHMAWI L., PESCH M., JUENGST C., SCHAUSS A. C., SCHRADER A. \& HÜLSKAMP M. 2014. Non-cell autonomous regulation of root hair patterning genes by WRKY75 in Arabidopsis. Plant Physiology. 165(1): 186-195. https://doi.org/10.1104/pp.113.233775

RODRÍGUEZ-SERRANO M., PAZMIÑO D. M., SPARKES I., ROCHETTI A., HAWES C., ROMERO-PUERTAS M. C. \& SANDALIO L. M. 2014. 2,4-dichlorophenoxyacetic acid promotes S-nitrosylation and oxidation of actin affecting cytoskeleton and peroxisomal dynamics. Journal of Experimental Botany. 65(17): 47834793. https://doi.org/10.1093/jxb/eru237

SALAZAR-HENAO J. E., VÉLEZ-BERMÚDEZ I. C. \& SCHMIDT W. 2016. The regulation and plasticity of root hair patterning and morphogenesis. Development. 143(11): 1848-1858. https://doi.org/10.1242/dev.132845

SÁNCHEZ-CALDERÓN L., IBARRA-CORTÉS M. E. \& ZEPEDA-JAZO I. 2013. Root development and abiotic stress adaptation: 135-168. In: VAHDATI K. \& LESLIE C. (eds). Abiotic stress - Plant responses and applications in agriculture. Intech Open Science, London.

SCHIEFELBEIN J. 2003. Cell fate specification in the epidermis: A common patterning mechanism in the root and the shoot. Current Opinion in Plant Biology. 6(1): 74-78. https://doi.org/10.1016/S136952660200002X

SCHIEFELBEIN J. W. \& SOMERVILLE C. 1990. Genetic control of root hair development in Arabidopsis thaliana. Plant Cell. 2(3): 235-243. https://doi.org/10.1105/tpc.2.3.235

SCHIEFELBEIN J., GALWAY M., MASUCCI J. \& FORD G. 1993. Pollen tube and root hair tip growth is disrupted in a mutant of Arabidopsis thaliana. Plant Physiology. 103(3): 979-985. https://doi.org/10.1104/pp.103.3.979

SCHIEFELBEIN J., MASUCCI J. D. \& WANG H. 1997. Building a root: The control of patterning and morphogenesis during root development. Plant Cell. 9(7): 1089-1098. https://doi.org/10.1105/tpc.9.7.1089

SCHIEFELBEIN J., KWAK S. H., WIECKOWSKI Y., BARRON C. \& BRUEX A. 2009. The gene regulatory network for root epidermal cell-type pattern formation in Arabidopsis. Journal of Experimental Botany. 60(5): 15151521. https://doi.org/10.1093/jxb/ern339

SCHMIDT W., TITTEL J. \& SCHIKORA A. 2000. Role of hormones in the induction of iron deficiency responses in Arabidopsis roots. Plant Physiology. 122(4): 1109-1118. https://doi.org/10.1104/pp.122.4.1109

SCHNEIDER K, WELLS B, DOLAN L. \& ROBERTS K. 1997. Structural and genetic analysis of epidermal cell differentiation in Arabidopsis primary roots. Development. 124(9): 1789-1798.

SEDBROOK J. D. 2004. MAPS in plant cells: delineating microtubule growth dynamics and organisation. Current Opinion in Plant Biology. 7(6): 632-640. https://doi.org/10.1016/j.pbi.2004.09.017

SETTER M. G., SCHMID K. \& LUDEWIG U. 2015. Uncovering genes and ploidy involved in the high diversity in root hair density, length and response to local scarce phosphate in Arabidopsis thaliana. PLoS ONE. 10(3): e0120604. https://doi.org/10.1371/journal.pone.0120604

SHIN L. J., HUANG H. E., CHANG H., LIN Y. N., FENG T. Y. \& GER M. J. 2011. Ectopic ferredoxin I protein promotes root hair growth through induction of reactive oxygen species in Arabidopsis thaliana. Journal of Plant Physiology. 168(5): 434-440. https://doi.org/10.1016/j.jplph.2010.08.002

SILVERMAN F. P., ASSIAHMAH A. A. \& BUSH D. S. 1998. Membrane transport and cytokinin action in root hairs of Medicago sativa. Planta. 205(1): 23-31. http://www.jstor.org/stable/23385243 
TELFER A., BOLLMAN K. M. \& POETHIG R. S. 1997. Phase change and the regulation of trichome distribution in Arabidopsis thaliana. Development. 124(3): 645-654. https://doi.org/10.1242/dev.124.3.645

TRAW M. B. \& BERGELSON J. 2003. Interactive effects of jasmonic acid, salicylic acid, and gibberellin on induction of trichomes in Arabidopsis. Plant Physiology. 133(3): 1367-1375. https://doi.org/10.1104/pp.103.027086

TSAI S. L., HARRIS P. J. \& LOVELL P. H. 2004. Bands of root hairs are produced in tomato (Lycopersicum esculentum) in response to specific combinations of thermoperiods and photoperiods. New Zealand Journal in Crop and Horticultural Science. 32(1): 121-129. https://doi.org/10.1080/01140671.2004.9514286

VAN HENGEL A. J., BARBER C. \& ROBERTS K. 2004. The expression patterns of arabinogalactan-protein AtAGP30 and GLABRA2 reveal a role for abscisic acid in the early stages of root epidermal patterning. Plant Journal. 39(1): 70-83. https://doi.org/10.1111/j.1365-313X.2004.02104.x

WANG X. 2005. Regulatory functions of phospholipase D and phosphatidic acid in plant growth, development and stress responses. Plant Physiology. 139(2): 566-573. https://doi.org/10.1104/pp.105.068809

WEBB M., JOUANNIC S., FOREMAN J., LINSTEAD P. \& DOLAN L. 2002. Cell specification in the Arabidopsis root epidermis requires the activity of ECTOPIC ROOT HAIR 3 - a katanin P60 protein. Development. 129(1): 123-131.

XU C. R., LIU C., WANG Y. L., LI L. C., CHEN W. Q., XU Z. N. \& BAI S. N. 2005. Histone deacetylation affects expression of cellular patterning genes in the Arabidopsis root epidermis. Proceedings of the National Academy of Sciences. 102(40): 14469-14474. https://doi.org/10.1073/pnas.0503143102

YANG T., SAVAGE N. \& SCHMIDT W. 2007. Plasticity of root epidermal cell fate in response to nutrient starvation. 18th International Conference on Arabidopsis Research. P-116. TAIR accession publication: 501721882 [accessed Aug. 23 ${ }^{\text {rd }}, 2021$ ].

YU Q., LI P., LIANG N., WANG H., XU M. \& WU S. 2017. Cell fate specification in Arabidopsis roots requires coordinative action of lineage instruction and positional reprogramming. Plant Physiology. 175(2): 816-827. https://doi.org/10.1104/pp.17.00814

How to cite this article:

MCCARTHY-SUÁREZ I. 2021. Supra-physiological levels of gibberellins / DELLAs alter the patterning, morphology and abundance of root hairs in root tips of $A$. thaliana seedlings. J. Plant Develop. 28: 41-67. https://doi.org/10.47743/jpd.2021.28.1.886 